Cahiers $d u$ MONDE RUSSE

\section{Cahiers du monde russe}

Russie - Empire russe - Union soviétique et États indépendants

57/2-3 | 2016

Famille et mobilité sociale en Russie, XVle-XVIIle siècles

\title{
Rodstvennye Sviazi V Vysshikh Krugakh Znati Xvii Stoletiia I Zemlevladenie
}

[Landed property and family ties among the Muscovite elites, 17th century $]^{1}$

Propriété foncière et liens de famille au sein de l'élite moscovite au XVII siècle Landed property and family ties among the Muscovite elite in the seventeenth century

\section{Olga Kosheleva}

\section{(2) OpenEdition}

\section{Édition électronique}

URL : http://journals.openedition.org/monderusse/8372

DOI : 10.4000/monderusse. 8372

ISSN : $1777-5388$

Éditeur

Éditions de l'EHESS

\section{Édition imprimée}

Date de publication : 1 avril 2016

Pagination : $545-570$

ISBN : 978-2-7132-2541-3

ISSN : $1252-6576$

\section{Référence électronique}

Olga Kosheleva, «Rodstvennye Sviazi V Vysshikh Krugakh Znati Xvii Stoletiia I Zemlevladenie », Cahiers du monde russe [Онлайн], 57/2-3 | 2016, Выложить онлайн 01 avril 2019, Наводить справки в 03 mai 2019. URL : http://journals.openedition.org/monderusse/8372 ; DOI : 10.4000/ monderusse.8372

Ce document a été généré automatiquement le 3 mai 2019.

(c) École des hautes études en sciences sociales 


\section{Rodstvennye Sviazi V Vysshikh Krugakh Znati Xvii Stoletiia I Zemlevladenie}

[Landed property and family ties among the Muscovite elites, 17th century $]^{1}$

Propriété foncière et liens de famille au sein de l'élite moscovite au XVII siècle Landed property and family ties among the Muscovite elite in the seventeenth century

\section{Olga Kosheleva}

\section{NOTE DE L'ÉDITEUR}

1 [ОЛЬГА Е. КОШЕЛЕВА, «РОДСТВЕННЫЕ СВЯЗИ В ВЫСШИХ КРУГАХ ЗНАТИ XVII СТОЛЕТИЯ И ЗЕМЛЕВЛАДЕНИЕ»]

1 В ИССЛЕДОВАНИЯХ О РОССИЙСКОЙ ПРАВЯЩЕЙ ЭЛИТЕ XVI-XVII ВЕКОВ ОСНОВНОЕ ВНИМАНИЕ УДЕЛЯЕТСЯ СЛУЖБЕ, ПРИЧЕМ ГЛАВНУЮ ЦЕЛЬ СЛУЖБЫ БОЯРСКИХ РОДОВ ГОСУДАРЮ ИСТОРИКИ ОБЫКНОВЕННО ВИДЯТ В ОБРЕТЕНИИ И УДЕРЖАНИИ ВИДНОГО ПОЛОЖЕНИЯ ПРИ ДВОРЕ. ОЧЕВИДНО, ОДНАКО, ЧТО СЛУЖБА (В ДУМЕ, НА ВОЕВОДСТВЕ, В ВОЕННОМ ПОХОДЕ ИЛИ ПОСОЛЬСТВЕ) КАЗАЛАСЬ БОЯРАМ ХОТЯ И НЕОБХОДИМОЙ, НО ТЯЖКОЙ ОБЯЗАННОСТЬЮ, И ОНИ ПРЕДПОЧИТАЛИ НАХОДИТЬСЯ В СПОКОЙНОЙ ОБСТАНОВКЕ СВОЕГО БОГАТОГО ДОМА. ОТКРЫТО ГОВОРИТЬ ОБ ОТВРАЩЕНИИ К СЛУЖБЕ БЫЛО, КОНЕЧНО, НЕ ПРИНЯТО И ДАЖЕ ОПАСНО. ТЕМ НЕ МЕНЕЕ, ЭТИ НАСТРОЕНИЯ НАШЛИ ОТРАЖЕНИЕ В ЛИЧНЫХ БОЯРСКИХ ДОКУМЕНТАХ, КОТОРЫХ, К СОЖАЛЕНИЮ, СОХРАНИЛОСЬ МАЛО.

2 К ТАКОВЫМ ОТНОСИТСЯ ПЕРЕПИСКА КНЯЗЯ П.И. ХОВАНСКОГО. ВО ВРЕМЯ СВОЕЙ ОТЛУЧКИ НА СЛУЖБУ НА ДОН КНЯЗЬ РЕГУЛЯРНО ПЕРЕПИСЫВАЛСЯ С ЖЕНОЙ, СЫНОМ И МАТЕРЬЮ, 
ПРИЧЕМ ЕГО ИНТЕРЕСОВАЛА КАЖДАЯ МЕЛОЧЬ, ПРОИСХОДИВШАЯ В ЕГО СЕМЬЕ И ХОЗЯЙСТВЕ. КНЯЗЬ СТРАСТНО ЖЕЛАЛ, ЧТОБЫ ГОСУДАРЬ ОТПУСТИЛ ЕГО СО СЛУЖБЫ, И В КАЖДОМ ПИСЬМЕ УМОЛЯЛ ЖЕНУ СДЕЛАТЬ ДЛЯ ЭТОГО ВСЕ ВОЗМОЖНОЕ:

А ОБО МНЕ КОНЕЧНО НЕОПЛОШНО БЕЙТЕ ЧЕЛОМ, ЧТОБЫ МЕНЯ НЫНЕШНЕЙ ЗИМОЙ ВЗЯЛИ К МОСКВЕ [...] А ЕСТЬЛИ БЫ МНЕ БЫТЬ НА ДОНУ, И Я БЫ ПОСЛЕДНЮЮ РУБАШКУ С СЕБЯ ОТДАЛ НЕ У ДЕЛА БЫТЬ [...] МНЕ СВОЯ ГОЛОВА ЛУЧШЕ ВСЕГО СВЕТУ. ЕСТЬ ЛИ МОЕЙ ГОЛОВЫ НЕ БУДЕТ, ТО МНЕ И СВЕТУ БУДЕТ ПРЕСТАВЛЕНЬЕ [...] ВИЖУ ТО Я И САМ, ЧТО МНЕ С ВАМИ ДО ТОЙ ЗИМЫ НЕ ВИДЕТЬСЯ, ТОЛЬКО НЕ МОГУ, КОГДА НАМЕРЕНО МНЕ, ОТ ТОЙ СЛУЖБЫ ОТБИТЬСЯ [...] КАК БЫ НИБУДЬ ВЫРВАТЬСЯ НЫНЕЧА ЗИМОЮ ИЛИ ВЕСНОЮ, КАК БЫ НИБУДЬ С ДОНУ.

ЖЕНА КНЯЗЯ ЖДАЛА ЕГО ВОЗВРАЩЕНИЯ С РАВНЫМ НЕТЕРПЕНИЕМ:

ПОЖАЛУЙ, ОТЕЦ МОЙ, НЕ ИЗВОЛЬ МЕШКАТЬ НИ ЗА ЧЕМ, ИЗВОЛЬ ВСЕ ПОКИНУТЬ. ЕЙ, НАМ ВЕРА НЕ ИМЕЕТСЯ, ЧТО ОЧИ ТВОИ ВИДЕТЬ. ${ }^{2}$

В СЕМЬЯХ ВОЛНОВАЛИСЬ ЗА СВОИХ БЛИЗКИХ, НАХОДИВШИХСЯ НА СЛУЖБЕ. ТАК, МАТЬ КН. В.В. ГОЛИЦЫНА ПРОСИЛА СВОЕГО СЫНА-ПОЛКОВОДЦА СТАРАТЬСЯ ИЗБЕГАТЬ ВСТРЕЧ С НЕПРИЯТЕЛЕМ:

ДА И ТО, СВЕТ МОЙ, Я СЛЫШАЛА, ЧТО ТЕБЕ ВЕЛЕНО ПО ВЕСТЯМ ГЛЯДЕЧИ ИТТИ И В БЕЛГОРОД И МОЕ, СВЕТ, ... СЕРЦЕ О ТОМ СОКРУШИЛОС, ЧТО ИДЕШЬ В ТАКУЮ ДАЛНУЮ ДОРОГУ С МАЛЫМИ ЛЮДМИ И ТЫ, СВЕТ МОИ, ПОИДИ, ПРОВЕДАЮЧИ И НЕ ПОПАДИСЯ, СВЕТ МОИ, НЕПРИЯТЕЛЕМ В ГЛАЗА... ${ }^{3}$

КАК КН. ХОВАНСКОМУ БЫЛА НЕВЫНОСИМА ЕГО СЛУЖБА НА ДОНУ, ТАК ВАСИЛИЮ БОРИСОВИЧУ ШЕРЕМЕТЕВУ - ЕГО ВОЕВОДСТВО В КИЕВЕ, КУДА ОН БЫЛ НАЗНАЧЕН В 1658 Г. ПОСТОЯННО МЕНЯЮЩАЯСЯ ОБСТАНОВКА В УКРАИНЕ, ПЕРЕМЕНЫ В ПОЛИТИЧЕСКОЙ ОРИЕНТАЦИИ СОЮЗНИКОВ, ГЕТМАНОВ И СТАРШИН, ЖАЛОБЫ НА НЕГО ИЗ КИЕВА ЦАРЮ, А ТАКЖЕ И УПРЕКИ И ТРУДНОВЫПОЛНИМЫЕ УКАЗЫ ИЗ МОСКВЫ ОСЛОЖНЯЛИ ЕГО СЛУЖБУ ДО КРАЙНОСТИ. ПОСЛЕ ТРЕХ ЛЕТ ТАКОЙ ЖИЗНИ ВАСИЛИЙ БОРИСОВИЧ РЕШИЛСЯ САМОВОЛЬНО УЕХАТЬ ДОМОЙ. УЗНАВ ОБ ЭТОМ, ЦАРЬ АЛЕКСЕЙ МИХАЙЛОВИЧ НАПИСАЛ ЕМУ ТРИ ПИСЬМА В ОДИН ДЕНЬ, УВЕЩЕВАЯ, ГРОЗЯ И УПРАШИВАЯ НЕ ПОКИДАТЬ КИЕВА, ПОКА «ТО НАШЕ ВЕЛИКОГО ГОСУДАРЯ ДЕЛО В КОНЕЦ НЕ ПРИВЕДЕНО», И УБЕЖДАЯ ЕГО «ВО ОСКОРБЛЕНИЕ СЕБЕ НЕ СТАВИТЬ, А ПОСТАВИТЬ БЫ СЕБЕ В МИЛОСТЬ БОЖИЮ» ЦАРСКИЙ ЗАПРЕТ ЕХАТЬ В МОСКВУ

ХОРОШО ИЗВЕСТНА ИСТОРИЯ СЛУЖБЫ СТОЛЬНИКА А.И. БЕЗОБРАЗОВА. В 1689 Г. ОН БЫЛ НАЗНАЧЕН ВОЕВОДОЙ НА ДАЛЕКИЙ ТЕРЕК. БЕЗОБРАЗОВ, ПО СЛОВАМ О.В. НОВОХАТКО, ВОСПРИНЯЛ ЭТО НАЗНАЧЕНИЕ КАК КАТАСТРОФУ, КАК ССЫЛКУ - ЕГО ОТПРАВЛЯЛИ В ЖУТКУЮ ДАЛЬ ОТ ЕГО ЛЮБИМОГО СПАССКОГО, ОТ ПРУДОВ С РЫБОЙ, ОТ ЯБЛОНЬ И СМОРОДИНЫ, ОТ УСТРОЕННОГО БЫТА, ОТ НОВЫХ, УЖЕ НАМЕЧЕННЫХ ЗЕМЕЛЬНЫХ ПРИОБРЕТЕНИЙ. ${ }^{5}$

ПРЕДПРИНЯТЫЕ ИМ УХИЩРЕНИЯ ИЗБЫТЬ НЕПРИЯТНУЮ СЛУЖБУ ПРИВЕЛИ К ТРАГИЧЕСКОМУ КОНЦУ: СТОЛЬНИК БЫЛ КАЗНЕН.

ПОДОБНОЕ ОТНОШЕНИЕ К СЛУЖБЕ, БЫЛО, ВЕРОЯТНО, ПУСТЬ НЕ ВСЕОБЩИМ, НО ДОВОЛЬНО РАСПРОСТРАНЕННЫМ. КАРЬЕРНЫЙ УСПЕХ ПРИ ДВОРЕ, ВЫИГРЫШ МЕСТНИЧЕСКОГО СПОРА, ЦАРСКИЕ МИЛОСТИ ЯВЛЯЛИСЬ ДЛЯ ЗНАТИ НЕ САМОДОСТАТОЧНОЙ ЦЕЛЬЮ, А СРЕДСТВОМ СОХРАНЕНИЯ И ПРИУМНОЖЕНИЯ БЛАГОПОЛУЧИЯ СЕМЬИ. ПОЭТОМУ В ДАННОЙ СТАТЬЕ Я НАМЕРЕВАЮСЬ СМЕНИТЬ ИССЛЕДОВАТЕЛЬСКУЮ ОПТИКУ И ПОСМОТРЕТЬ НА СТРАТЕГИИ ЗНАТИ НЕ ЧЕРЕЗ ПОЛИТИЧЕСКУЮ, А ЧЕРЕЗ СЕМЕЙНУЮ ИСТОРИЮ. МОЯ ЗАДАЧА ПРОСЛЕДИТЬ СЕМЕЙНЫЕ ТАКТИКИ НАСЛЕДОВАНИЯ И БРАКОВ, А ТАКЖЕ СОПРОВОЖДАВШУЮ ИХ ЦИРКУЛЯЦИЮ ЗЕМЕЛЬНЫХ ИМЕНИЙ, С ТЕМ, ЧТОБЫ ПОНЯТЬ, 
СКЛАДЫВАЛИСЬ ЛИ С ПОМОЩЬЮ ЭТИХ ТАКТИК ОПРЕДЕЛЕННЫЕ СЕМЕЙНЫЕ КЛАНЫ. ВЫБРАВ ДЛЯ РАССМОТРЕНИЯ СВЯЗИ СЕМЕЙ ШЕРЕМЕТЕВЫХ, ОДОЕВСКИХ И ЧЕРКАССКИХ, СЛЕДУЕТ ПОСТАВИТЬ ВОПРОС: БЫЛИ ЛИ ОНИ ТИПИЧНЫ И ДЛЯ ДРУГИХ ЗНАТНЫХ СЕМЕЙ? С ЭТОЙ ЦЕЛЬЮ В СТАТЬЕ ОСУЩЕСТВЛЯЕТСЯ СРАВНЕНИЕ БРАЧНЫХ ТАКТИК ДРУГОЙ, РАВНОЙ ПО ЗНАЧИМОСТИ, ВЕТВИ РОДА ШЕРЕМЕТЕВЫХ.

7 ПРЕДВАРИТЕЛЬНО СЛЕДУЕТ СКАЗАТЬ НЕСКОЛЬКО СЛОВ О ПОНЯТИИ «КЛАН» В ИСТОРИОГРАФИИ О РОССИЙСКОМ БОЯРСТВЕ. ВПЕРВЫЕ ГИПОТЕЗА О ТОМ, ЧТО ПОЛИТИЧЕСКАЯ КУЛЬТУРА МОСКОВСКОГО ГОСУДАРСТВА ОСНОВЫВАЛАСЬ НА БОРЬБЕ РОДОВЫХ КЛАНОВ ЗА ВХОЖДЕНИЕ В ЭЛИТНЫЕ КРУГИ ГОСУДАРСТВЕННОГО УПРАВЛЕНИЯ ПРИ САМОДЕРЖЦЕ, БЫЛА ВЫДВИНУТА НЭНСИ КОЛЛМАН 6 И ОКАЗАЛАСЬ ПОЛОЖИТЕЛЬНО ВОСПРИНЯТА ИСТОРИКАМИ ${ }^{7}$. ОДНАКО САМО ПОНЯТИЕ «КЛАН» ДО СИХ ПОР ОСТАЕТСЯ РАСПЛЫВЧАТЫМ. ВАЛЕРИЯ КИВЕЛЬСОН ФАКТИЧЕСКИ УРАВНИВАЕТ ПОНЯТИЯ «КЛАН» И «РОД»:

Boyar clans maintained lengthy genealogical records, all traced through the male line. Individuals calculated their standing within their own clans and negotiated the status of their clans relative to others through a complicated formula of genealogical seniority, in order of descent in the male line from a real or imaginary male progenitor. ${ }^{8}$

ИССЛЕДОВАТЕЛЬНИЦА УПОТРЕБЛЯЕТ И ПОНЯТИЕ «еxtended clan», ПОНИМАЯ ПОД ЭТИМ СОВОКУПНОСТЬ РАЗНЫХ ВЕТВЕЙ ОДНОГО РОДА९. МАРШАЛЛ ПО ТАКЖЕ СТАВИТ ЗНАК РАВЕНСТВА МЕЖДУ ТЕРМИНАМИ «РОД» И «КЛАН». ОН ВЫДЕЛЯЕТ ТРИ ПОЛИТИЧЕСКИХ СИЛЫ ПРИ МОСКОВСКОМ ДВОРЕ XVII В.: 1) САМОДЕРЖЕЦ, 2) ЕГО ПРИДВОРНАЯ СЛУЖИЛАЯ ЭЛИТА («elite servitors») И 3) КЛАНЫ, ЧАСТИЧНО ВХОДЯЩИЕ В ЭТУ ЭЛИТУ. ПОСЛЕДНИЕ, В ОТЛИЧИЕ ОТ НЕФОРМАЛЬНЫХ «patron-client circles», ЭТО - БОЛЕЕ-МЕНЕЕ ЛЕГИТИМИЗИРОВАННЫЕ РОДСТВЕННЫЕ ГРУППЫ («kin groups») ${ }^{10}$ П.В.СЕДОВ, РАССМАТРИВАВШИЙ ПОЛИТИЧЕСКУЮ БОРЬБУ ПРИ ДВОРЕ ЦАРЕЙ АЛЕКСЕЯ МИХАЙЛОВИЧА И ФЕДОРА АЛЕКСЕЕВИЧА, ОБЪЕДИНЯЕТ РОДСТВО, СВОЙСТВО И КЛИЕНТЕЛУ В ПОНЯТИИ «КЛАНОВЫЕ СВЯЗИ»:

КЛАНОВЫЕ СВЯЗИ СЛУЖИЛОГО ЧЕЛОВЕКА БЫЛИ РЕЗУЛЬТАТОМ ВСЕГО ЕГО ЖИЗНЕННОГО ПУТИ. РОДСТВЕННЫЕ УЗЫ С РОЖДЕНИЯ ОПРЕДЕЛЯЛИ СТАТУС И НАЧАЛО СЛУЖЕБНОЙ КАРЬЕРЫ. ЗАТЕМ СЛУЖИЛЫЙ ЧЕЛОВЕК САМ ЖЕНИЛСЯ, УСТРАИВАЛ БРАКИ СВОИХ ДЕТЕЙ И ТАКИМ ОБРАЗОМ РАСШИРЯЛ СВОЕ РОДСТВО. ЗА ГОДЫ СЛУЖБЫ [...] МЕЖДУ СЛУЖИЛЫМИ ЛюДЬМИ СКЛАДЫВАЛИСЬ ОТНОШЕНИЯ ПОКРОВИТЕЛЬСТВА И «ПРИЯТСТВА». ${ }^{11}$

ПОНЯТИЕ «КЛАН» НЕВОЗМОЖНО ТОЧНО ОПРЕДЕЛИТЬ В РАМКАХ ПОНЯТИЙНОЙ СИСТЕМЫ XVII В., ПОСКОЛЬКУ ЕГО НЕ ФИКСИРУЮТ СЛОВАРИ ХІ-XVIII ВЕКОВ: ОНО ЯВЛЯЕТСЯ СОВРЕМЕННЫМ ИСТОРИОГРАФИЧЕСКИМ КОНСТРУКТОМ. НЕ СЛУЧАЙНО, В ИССЛЕДОВАТЕЛЬСКОЙ ЛИТЕРАТУРЕ О «КЛАНАХ» ВСЕГДА ГОВОРИТСЯ АБСТРАКТНО - ИХ НАПОЛНЕНИЕ РЕАЛЬНЫМИ ИСТОРИЧЕСКИМИ ФИГУРАМИ ОТСУТСТВУЕТ. ТЕМ НЕ МЕНЕЕ, В ДАННОЙ СТАТЬЯ Я ВОСПОЛЬЗУЮСЬ ИМЕННО ТЕРМИНОМ «КЛАН», ОСОЗНАВАЯ ЕГО УСЛОВНОСТЬ. ПОД «КЛАНОМ» Я БУДУ ИМЕТЬ В ВИДУ ПРОЧНЫЕ РОДСТВЕННЫЕ СВЯЗИ НЕСКОЛЬКИХ СЕМЕЙ ИЗ БОЯРСКИХ РОДОВ И ПОСТАРАЮСЬ НАПОЛНИТЬ ЕГО КОНКРЕТНЫМ ИСТОРИЧЕСКИМ СОДЕРЖАНИЕМ. 


\section{Семейные ценности знати}

10 ЧТО ЖЕ, ПОМИМО ЦАРСКОЙ СЛУЖБЫ, БЫЛО ЗНАЧИМЫМ В ЖИЗНЕННЫХ СТРАТЕГИЯХ БОЯР? ВАЖНЕЙШЕЙ В НИХ БЫЛА ЭКОНОМИЧЕСКАЯ СОСТАВЛЯЮЩАЯ - ПРИОБРЕТЕНИЕ ЗЕМЛИ И КРЕСТЬЯН. ЕГО ИСТОЧНИКОМ ЯВЛЯЛИСЬ НЕ ТОЛЬКО ЦАРСКИЕ ПОЖАЛОВАНИЯ, НО ТАКЖЕ РОДОВОЕ НАСЛЕДСТВО И ПРИДАННОЕ. ОДНАКО ЛЮБОЕ БЛАГОПОЛУЧИЕ НЕМНОГО ЗНАЧИЛО БЕЗ ЗДОРОВОГО МУЖСКОГО ПОТОМСТВА, ГОТОВОГО ПРОДОЛЖИТЬ ЖИЗНЬ РОДА ${ }^{12}$. РОД, РОДСТВЕННАЯ ГРУППА И ЕЕ ОБЩЕЕ ПРОИСХОЖДЕНИЕ («ПОРОДНАЯ ЧЕСТЬ») ТАКЖЕ ЯВЛЯЛИСЬ ОДНОЙ ИЗ ГЛАВНЫХ ЦЕННОСТЕЙ ЗНАТИ. ПОТОМУ ТАК РЬЯНО ВЕЛИСЬ МЕСТНИЧЕСКИЕ СПОРЫ, ЧТО УЧИНИТЬ «ПОРУХУ» СВОЕМУ РОДУ, УСТУПИВ В НИХ, БЫЛО ПОЗОРОМ. КРЕПКО ДЕРЖАЛОСЬ И ПРЕДСТАВЛЕНИЕ О ТОМ, ЧТО ВОТЧИННАЯ ЗЕМЛЯ НЕ ДОЛЖНА УХОДИТЬ ИЗ РОДА, О ЧЕМ ГОВОРИТ МНОЖЕСТВО СУДЕБНЫХ ДЕЛ, ОПРОТЕСТОВЫВАЮЩИХ ЗАВЕЩАНИЯ, В КОТОРЫХ ЗЕМЛЯ ПЕРЕДАВАЛАСЬ ПО ЖЕНСКОЙ линии.

ОБЫЧАЙ ДОЛЕВОГО НАСЛЕДОВАНИЯ ТОЖЕ, ВЕРОЯТНО, ОТНОСИЛСЯ К МОРАЛЬНЫМ ЦЕННОСТЯМ СЕМЬИ. В ОТЛИЧИЕ ОТ ИСТОРИКОВ, САМИ БОЯРЕ НЕ ВИДЕЛИ ЗЛА В ДРОБЛЕНИИ РОДОВЫХ ЗЕМЕЛЬ, ОТДАННЫХ ВСЕМ СЫНОВЬЯМ ПОРОВНУ, И НЕ ОПАСАЛИСЬ ЧЕРЕЗ НЕГО ИЗМЕЛЬЧАНИЯ РОДА. У НАС НЕТ ВЫСКАЗЫВАНИЙ ОБ ЭТОМ СОВРЕМЕННИКОВ, ВИДИМО ОБ ИНОМ ВАРИАНТЕ ОНИ НЕ ЗАДУМЫВАЛИСЬ, ХОТЯ, ВОЗМОЖНО, И ЗНАЛИ О ТРАДИЦИЯХ НЕДОЛЕВОГО НАСЛЕДОВАНИЯ ОТ СЛУЖИЛЫХ ИНОЗЕМЦЕВ, НЕКОТОРЫЕ ИЗ КОТОРЫХ БЫЛИ МЛАДШИМИ ДЕТЬМИ В СЕМЬЕ, ОСТАВШИМИСЯ БЕЗ НЕДВИЖИМОГО НАСЛЕДСТВА $^{13}$. УКАЗ ПЕТРА О ЕДИНОНАСЛЕДИИ (1714 Г.) СРАЗУ ВЫЗВАЛ ПАССИВНОЕ СОПРОТИВЛЕНИЕ ДВОРЯН ${ }^{14}$, А ПОСЛЕ СМЕРТИ ЦАРЯ РОССИЙСКОЕ ДВОРЯНСТВО, ЧАСТО СЧИТАЮЩЕЕСЯ ПОЛИТИЧЕСКИ МАЛОАКТИВНЫМ И НЕ УМЕЮЩИМ БОРОТЬСЯ ЗА СВОИ ПРАВА, БЫСТРО СУМЕЛО ЗАКОНОДАТЕЛЬНО ВЕРНУТЬ ДРЕВНЮЮ ТРАДИЦИЮ ДОЛЕВОГО НАСЛЕДИЯ ${ }^{15}$. В ОБРАЩЕНИИ СЕНАТА К ИМПЕРАТРИЦЕ АННЕ ИОАННОВНЕ ИЗЪЯСНЯЛИСЬ ВСЕ ЕЕ ПРЕИМУЩЕСТВА ${ }^{16}$. КАК ПОКАЗЫВАЮТ ИССЛЕДОВАНИЯ ПОСЛЕДНИХ ДЕСЯТИЛЕТИЙ, НЕУДОБСТВА ДОЛЕВОГО НАСЛЕДОВАНИЯ КОМПЕНСИРОВАЛИ БРАЧНЫЕ СОЮЗЫ И ЖЕНСКАЯ ЧАСТЬ ОБЩЕСЕМЕЙНОЙ ЗЕМЕЛЬНОЙ СОБСТВЕННОСТИ ${ }^{17}$, А ТАКЖЕ ЦАРСКИЕ ПОЖАЛОВАНИЯ, ПОЭТОМУ ОБНИЩАНИЯ ЗНАТИ В РЕЗУЛЬТАТЕ ТРАДИЦИИ ДОЛЕВОГО НАСЛЕДОВАНИЯ НЕ ПРОИСХОДИЛО. ОДНАКО, КАК МЫ УВИДИМ НИЖЕ, РАВНОГО РАЗДЕЛА НАСЛЕДИЯ ПРИДЕРЖИВАЛИСЬ ДАЛЕКО НЕ ПЕДАНТИЧНО, В ЕГО РАМКАХ БЫЛИ ВОЗМОЖНЫ РАЗНЫЕ ВАРИАНТЫ. ПРИНЦИП ИМУЩЕСТВЕННОГО РАВЕНСТВА ДЕТЕЙ В СЕМЬЕ КАК ВОПЛОЩЕНИЕ СПРАВЕДЛИВОСТИ БЫЛ ИДЕАЛОМ, НО НА ПРАКТИКЕ ОН РЕАЛИЗОВЫВАЛСЯ С ТРУДОМ. К ХЛОПОТАМ О ПРИЖИЗНЕННОМ БЛАГОДЕНСТВИИ ДОБАВЛЯЛИСЬ ЗАБОТЫ О БЛАГОПОЛУЧИИ ПОСЛЕ СМЕРТИ. НАИЛУЧШАЯ ОРГАНИЗАЦИЯ ПОМИНОВЕНИЯ УСОПШИХ ЧЛЕНОВ СЕМЬИ СЧИТАЛАСЬ ВАЖНЕЙШИМ ДЕЛОМ ${ }^{18}$. БОЯРИН, КН. НИКИТА ИВАНОВИЧ ОДОЕВСКИЙ В СВОЕЙ ДУХОВНОЙ ГРАМОТЕ ПИСАЛ:

А БУДЕ ВОЛЕЮ БОЖИЕЮ ПРАВНУЧАТАМ МОИМ КОМУ СЛУЧИТСЯ СМЕРТЬ, А СЫНОВЕЙ И ДОЧЕРЕЙ НЕ ОСТАНЕТСЯ, И ТОГО ДОЛЮ ВОТЧИНЫ И ДВОРЫ В КИТАЕ ГОРОДЕ И В БЕЛОМ ГОРОДЕ НА ТВЕРСКОЙ УЛИЦЕ НЕ ПРОДАВАТЬ И НЕ ЗАЛОЖИТЬ, И ЗА СЕСТРАМИ, И ЗА ДОЧЕРЬМИ В ПРИДАННЫЕ НЕ ОТДАТЬ, А ОТДАТЬ ТЕ ДВОРЫ БРАТЬЯМ И РОДУ, И КТО ПО НИХ МУЖСКОГО ПОЛУ ОДОЕВСКИХ ОСТАНЕТСЯ, ЧТОБ ТЕ ДВОРЫ ИЗ РОДУ ВЕЧНО НЕ ВЫШЛИ, ДЛЯ ТОГО, ЧТО НА ТЕХ ДВОРЕХ ПОСТРОЕНЫ ЦЕРКВИ БОЖИИ ДЛЯ ПОМИНОВЕНИЯ РОДИТЕЛЕЙ. [КУРСИВ МОЙ - О.К. $]^{19}$ 
ПОКАЗАТЕЛЬНО, ЧТО КН.Н.И. ОДОЕВСКИЙ, ПОМИМО МОНАСТЫРСКОГО ПОМИНОВЕНИЯ, ОРГАНИЗОВАЛ СОБСТВЕННОЕ, РОДОВОЕ, В ЦЕРКВЯХ, ПОСТРОЕННЫХ НА СВОЕМ МОСКОВСКОМ ДВОРЕ, И ЗАБОТУ О НИХ ОСТАВИЛ НА ПОПЕЧЕНИЕ СВОИХ ПОТОМКОВ «ВЕЧНО ${ }^{20}$. ИНАЧЕ ГОВОРЯ, ГЛАВЕ БОЛЬШОЙ СЕМЬИ КАЗАЛОСЬ КРАЙНЕ ВАЖНЫМ, ЧТОБЫ В БУДУЩЕМ ДЛЯ ВСЕХ УСОПШИХ ЧЛЕНОВ РОДА ОСУЩЕСТВЛЯЛОСЬ ПОМИНОВЕНИЕ.

КАК ИЗВЕСТНО, ОБШИРНАЯ ЗЕМЕЛЬНАЯ СОБСТВЕННОСТЬ САМА ПО СЕБЕ НЕ ОБЕСПЕЧИВАЛА ЕЕ ВЛАДЕЛЬЦАМ ПОЛИТИЧЕСКОГО ВЛИЯНИЯ ПРИ ЦАРСКОМ ДВОРЕ. НАПРОТИВ, БЛИЗОСТЬ К ЦАРСКОЙ ОСОБЕ СУЛИЛА ПЕРСПЕКТИВУ РАЗБОГАТЕТЬ. ПОЭТОМУ МОЖНО ПРЕДПОЛОЖИТЬ, ЧТО БОЯРЕ (КАК И ДРУГИЕ СОЦИАЛЬНЫЕ ГРУППЫ НАСЕЛЕНИЯ) СТРЕМИЛИСЬ ИМЕТЬ КАК МОЖНО БОЛЬШЕ ЗЕМЛИ И КРЕСТЬЯН НЕ СТОЛЬКО РАДИ ВЛАСТИ, СКОЛЬКО РАДИ ДОХОДОВ, КОТОРЫЕ, В ЧАСТНОСТИ, ПОЗВОЛЯЛИ ДЕЛАТЬ БОГАТЫЕ ВКЛАДЫ В МОНАСТЫРИ НА ПОМИНОВЕНИЕ СЕБЕ И СВОЕМУ РОДУ. ЭТОЙ ПРАКТИКЕ НЕ ПОМЕШАЛ ДАЖЕ ЗАПРЕТ НА ПЕРЕДАЧУ РОДОВЫХ И ВЫСЛУЖЕННЫХ ЗЕМЕЛЬ В МОНАСТЫРИ ДЛЯ ПОМИНОВЕНИЯ, ЗАФИКСИРОВАННЫЙ В СОЗДАННОМ ПРИ УЧАСТИИ ТОГО ЖЕ КН.Н.И. ОДОЕВСКОГО СОБОРНОМ УЛОЖЕНИИ 1649Г. (ГЛ. XVII). ОБХОДЯ ЕГО, ЗЕМЛЕВЛАДЕЛЬЦЫ ПЕРЕД СМЕРТЬЮ ПРОДАВАЛИ СВОИ ИМЕНИЯ (ЧАСТО РОДСТВЕННИКАМ ИЛИ ДУШЕПРИКАЗЧИКАМ), А ДЕНЬГИ ОТ ПРОДАЖИ ОТДАВАЛИ В ТЕ ЖЕ МОНАСТЫРИ НА ПОМИНОВЕНИЕ. ТАК, КН. МАТВЕЙ ВАСИЛЬЕВИЧ ПРОЗОРОВСКИЙ ПРОДАЛ СВОЕМУ ДУШЕПРИКАЗЧИКУ КН. МИХАИЛУ ЯКОВЛЕВИЧУ ЧЕРКАССКОМУ СЕЛО АЙРАТ АРЗАМАССКОГО УЕЗДА ЗА КОЛОССАЛЬНУЮ СУММУ, 8 ТЫСЯЧ РУБ., ИЗ КОТОРОЙ 7 ТЫСЯЧ ПРЕДНАЗНАЧАЛИСЬ НА ПОМИНОВЕНИЕ ${ }^{21}$.

ДТВЛЕНИЯ ЗНАТИ О ТОМ, ЧТО ИМЕННО ДОРОГО И ВАЖНО ДЛЯ БУДУЩЕГО СЕМЬИ, ОТРАЗИЛИСЬ В СЛОВАХ КН. ПЕТРА ИВАНОВИЧА ХОВАНСКОГО В ОДНОМ ИЗ ПИСЕМ К ЖЕНЕ:

А НЫНЕ ЗА ВОЛЕЮ ГОСУДАРЬСКОЮ, ЧТО МНЕ ВЕЛЕНО... ИЗ ЗАПОРОГ ИТИТЬ В КРЫМ.

А ЕСТЬЛИ ЧТО НАДО МНОЮ, ТО ВОЛЯ БОЖЬЯ И УЧИНИТСЯ, - И У МЕНЯ ОСТАНЕТСЯ

ПОСЛЕ МЕНЯ КНЯЗЬ АНДРЕЙ [СЫН - О.К.], ТАК ВЕЧНАЯ СЛАВА БУДЕТ, ЧТО Я БЫЛ В КРЫМЕ, А ТО НИКТО НЕ БЫВАЛ В КРЫМЕ ОТ НАЧАЛА СВЕТУ.22

ТАКИМ ОБРАЗОМ, ДАЖЕ ПОСЛЕ СМЕРТИ КНЯЗЯ, ДОБЫТАЯ ИМ ВОИНСКАЯ «СЛАВА» БУДЕТ СОХРАНЕНА В ПАМЯТИ, ПРИБАВИТ ЧЕСТИ ЕГО СЫНУ, СТАНЕТ ЧАСТЬЮ РОДОВОЙ СЛАВЫ.

ИТАК, ПОМИНОВЕНИЕ ДУШИ НА ТОМ СВЕТЕ И СЛАВА ВЕЧНАЯ (memoria) НА ЗЕМЛЕ - ВОТ О КАКОМ БУДУЩЕМ ДУМАЛИ В БОЯРСКИХ СЕМЬЯХ (НАВЕРНОЕ, И НЕ ТОЛЬКО В БОЯРСКИХ), НО ОСУЩЕСТВЛЕНИЕ ЭТОГО НАПРЯМУЮ ЗАВИСЕЛО ОТ НАЛИЧИЯ ПОТОМСТВА, КОТОРОЕ СОВЕРШАЛО БЫ ПОМИНОВЕНИЕ РОДИТЕЛЕЙ, ИМЕЯ К ТОМУ ЭКОНОМИЧЕСКИЕ ВОЗМОЖНОСТИ, И ПЕРЕДАВАЛО БЫ СЛАВУ ИЗ ПОКОЛЕНИЯ В ПОКОЛЕНИЕ, ПОДДЕРЖИВАЯ ЕЕ «ВЕЧНОСТЬ» ${ }^{23}$. ЭТИ ЦЕННОСТИ, КАК ПРЕДСТАВЛЯЕТСЯ, ЛЕЖАЛИ В ОСНОВЕ СЕМЕЙНЫХ СТРАТЕГИЙ.

\section{Семья боярина Ф.И. Шереметева и его потомков кн. Одоевских: Браки и движение наследственной массы}

17 УВИДЕТЬ ПРАКТИКУ ОРГАНИЗАЦИИ БРАКОВ И СЕМЕЙНОГО НАСЛЕДИЯ В ХVII В ВОЗМОЖНО ДЛЯ РОССИЙСКОЙ ИСТОРИИ СЕМЬИ ЛИШЬ В РЕДКИХ СЛУЧАЯХ, ИЗ-ЗА УТРАТЫ СЕМЕЙНЫХ АРХИВОВ ЗНАТИ В ПЛАМЕНИ ВОЙН И УРАГАНЕ РЕВОЛЮЦИЙ. В ЛУЧШЕМ 
СЛУЧАЕ, МЫ ИМЕЕМ ЛИШЬ РАЗРОЗНЕННЫЕ МАТЕРИАЛЫ ${ }^{24}$. СУЩЕСТВУЮТ, ОДНАКО, ИСКЛЮЧЕНИЯ. ТАК, ЧАСТНЫЙ АРХИВ РОДА ШЕРЕМЕТЕВЫХ СОХРАНИЛСЯ БЛАГОДАРЯ ГР. С.Д. ШЕРЕМЕТЕВУ (1844-1918), СОБРАВШЕМУ ДОКУМЕНТЫ ПО ИСТОРИИ СВОЕЙ СЕМЬИ И ЧАСТИЧНО ИХ ОПУБЛИКОВАВШЕМУ. НА ЭТОМ ОСНОВАНИИ, А.П. БАРСУКОВ ПРОИЗВЕЛ ТЩАТЕЛЬНУЮ РЕКОНСТРУКЦИЮ ИСТОРИИ РОДА ШЕРЕМЕТЕВЫХ В 8-МИ ТОМАХ ${ }^{25}$.

МАТЕРИАЛЫ ШЕРЕМЕТЕВЫХ ВКЛЮЧАЮТ В СЕБЯ, В ЧАСТНОСТИ, ДУХОВНЫЕ ЗАВЕЩАНИЯ XVII В., ИМЕВШИЕ ОТНОШЕНИЯ К РОДУ ШЕРЕМЕТЕВЫХ, ОСОБЕННО ЦЕННЫЕ ДЛЯ НАШЕЙ ТЕМЫ. ОНИ ДАЮТ ВОЗМОЖНОСТЬ УВИДЕТЬ БРАЧНЫЕ СТРАТЕГИИ ЧЛЕНОВ РОДА, ДВИЖЕНИЕ НАСЛЕДСТВЕННОЙ МАССЫ ЧЕРЕЗ ВЕСЬ XVII В., И ПРОАНАЛИЗИРОВАТЬ ПРЕДПОСЫЛКИ СТАВШЕГО ШИРОКО ИЗВЕСТНЫМ БРАЧНОГО АПОФЕОЗА, КОГДА САМАЯ БОГАТАЯ НЕВЕСТА РОССИИ, КНЯЖНА ВАРВАРА МИХАЙЛОВНА ЧЕРКАССКАЯ, В 1743 Г. ВЫШЛА ЗАМУЖ ЗА САМОГО БОГАТОГО ЖЕНИХА РОССИИ, СЫНА ИЗВЕСТНОГО ФЕЛЬДМАРШАЛА, ПЕТРА БОРИСОВИЧА ШЕРЕМЕТЕВА ${ }^{26}$. ПРИНАДЛЕЖАВШИЕ ИМ ЗЕМЛИ (44 ИМЕНИЯ И 140 ТЫС. КРЕПОСТНЫХ) ОХВАТЫВАЛИ ЗНАЧИТЕЛЬНУЮ ЧАСТЬ ТЕРРИТОРИИ РОССИИ, ОДНАКО, ЧТО ХАРАКТЕРНО, ЭТО НЕ ПРИВЕЛО К ПОЛИТИЧЕСКОМУ ВОЗВЫШЕНИЮ ЭТОЙ СЕМЬИ. ДАННАЯ «СЕМЕЙНАЯ ИСТОРИЯ» (КОТОРАЯ ГОРАЗДО ШИРЕ ИСТОРИИ ОДНОГО РОДА ШЕРЕМЕТЕВЫХ) ЦЕННА ДЛЯ НАС КАК ЯРКИЙ ПРИМЕР ОБРАЗОВАНИЯ БОЯРСКИХ КЛАНОВ ЧЕРЕЗ БРАЧНЫЕ И НАСЛЕДСТВЕННЫЕ ПРАКТИКИ, В ПЕРИОД ПРАВЛЕНИЯ ПЕРВЫХ РОМАНОВЫХ. РАССМОТРИМ ЕЕ ПОДРОБНО.

БОЯРЕ РОМАНОВЫ, ОСНОВАВШИЕ В 1613 Г. НОВУЮ ЦАРСКУЮ ДИНАСТИЮ, СЧИТАЛИ СЕБЯ ПРЯМЫМИ НАСЛЕДНИКАМИ РЮРИКОВИЧЕЙ ЧЕРЕЗ МОСКОВСКУЮ ЛИНИЮ ДАНИЛОВИЧЕЙ, НА ТОМ ОСНОВАНИИ, ЧТО ПЕРВОЙ ЖЕНОЙ ЦАРЯ ИВАНА ГРОЗНОГО БЫЛА БОЯРЫНЯ АНАСТАСИЯ РОМАНОВНА ЗАХАРЬИНА-ЮРЬЕВА, ИЗ РОДА КОТОРОЙ ПРОИСХОДИЛИ И РОМАНОВЫ. С УТРАТОЙ ПРЯМЫХ НАСЛЕДНИКОВ СВОЙСТВО ПО ЖЕНСКОЙ ЛИНИИ ПРИОБРЕЛО БОЛЬШУЮ ЗНАЧИМОСТЬ И В ЦАРСКОЙ, И В БОЯРСКИХ СЕМЬЯХ. НА ЭТОМ ЗЫБКОМ ОСНОВАНИИ ПЕРВЫЕ РОМАНОВЫ НАЗЫВАЛИ ЦАРЯ ФЕДОРА ИОАННОВИЧА СВОИМ «ДЕДОМ», А ГРОЗНОГО - ПРАДЕДОМ ${ }^{27}$, И ДАЖЕ ЕГО ЧЕТВЕРТУЮ ЖЕНУ АННУ КОЛТОВСКУЮ СЧИТАЛИ ОДНИМ ИЗ ЧЛЕНОВ СВОЕГО РОДА (ИЛИ, СКОРЕЕ, ДИНАСТИИ) И ПОСЫЛАЛИ ЕЙ ПОДАРКИ В МОНАСТЫРЬ, ГДЕ ОНА ЖИЛА ДО СВОЕЙ СМЕРТИ В $1626 \Gamma^{28}$ С ПРИХОДОМ РОМАНОВЫХ К ВЛАСТИ, ТРИ МОГУЩЕСТВЕННЫХ В XVI ВЕКЕ РОДА, ШЕРЕМЕТЕВЫ, КН. ЧЕРКАССКИЕ И КН. ОДОЕВСКИЕ, НАХОДИВШИЕСЯ В ОПАЛЕ ${ }^{29}$ (ПЕРВЫЕ ДВА - ПРИ ГОДУНОВЕ, ПОСЛЕДНИЙ - ПРИ ГРОЗНОМ), НАЧАЛИ НОВУЮ, СПОКОЙНУЮ ЖИЗНЬ. ТЯЖЕЛО ПЕРЕЖИВ СМУТНОЕ ВРЕМЯ, ИХ ПРЕДСТАВИТЕЛИ ВОШЛИ В БОЯРСКУЮ ДУМУ ПРИ ЦАРЕ МИХАИЛЕ РОМАНОВЕ И ЗАНЯЛИ В НЕЙ ВЕДУЩИЕ ПОЗИЦИИ. ЭТИ ФАМИЛИИ ИМЕЛИ РАЗНОЕ ПРОИСХОЖДЕНИЕ: ШЕРЕМЕТЕВЫ ВЫШЛИ ИЗ СТАРОМОСКОВСКОГО БОЯРСКОГО РОДА, КН. ОДОЕВСКИЕ - ИЗ РОДА ВЕРХНЕОКСКИХ УДЕЛЬНЫХ КНЯЗЕЙ, КН. ЧЕРКАССКИЕ СЛУЖИЛЫЕ КНЯЗЬЯ, ВЫЕХАВШИЕ В РАЗНОЕ ВРЕМЯ ИЗ КАБАРДЫ НА СЛУЖБУ К МОСКОВСКОМУ ГОСУДАРЮ. ОЗНАЧАЛИ ЛИ ЭТИ «ТИТУЛЬНЫЕ» РАЗЛИЧИЯ КАКОЕ-ЛИБО РОДОСЛОВНОЕ НЕРАВЕНСТВО ЭТИХ РОДОВ ПРИ РОМАНОВЫХ? «ЛАКМУСОВОЙ БУМАЖКОЙ» ДЛЯ ОПРЕДЕЛЕНИЯ СТЕПЕНИ ЗНАЧИМОСТИ РОДА ЯВЛЯЛОСЬ ПРОХОЖДЕНИЕ ЕГО ЧЛЕНОВ В ДУМНЫЙ БОЯРСКИЙ ЧИН ЧЕРЕЗ ЧИН ОКОЛЬНИЧЕГО. СРАЗУ ПОЛУЧАЛИ БОЯРСКИЙ ЧИН ВСЕ СЛУЖИЛЫЕ КНЯЗЬЯ, В ТО ВРЕМЯ КАК НЕКОТОРЫЕ СТАРОМОСКОВСКИЕ БОЯРСКИЕ РОДЫ И БЫВШИЕ УДЕЛЬНЫЕ КНЯЗЬЯ ИНОГДА ЗАДЕРЖИВАЛИСЬ В ОКОЛЬНИЧИХ ${ }^{30}$. НО НИ ШЕРЕМЕТЕВЫ, НИ КН. ОДОЕВСКИЕ НЕ ПРОХОДИЛИ ЧЕРЕЗ ЧИН ОКОЛЬНИЧЕГО. КАК И ЧЕРКАССКИЕ, ОНИ СРАЗУ ЖАЛОВАЛИСЬ В БОЯРСКИЙ ЧИН, Т.Е. И В ЭТОМ ОТНОШЕНИИ МЕЖДУ ЭТИМИ РОДАМИ НЕ БЫЛО РАЗНИЦЫ. 
- ОБА РОДА ПРОИСХОДИЛИ ОТ БОЯРИНА ФЕДОРА АНДРЕЕВИЧА КОШКИ. В XVI В. ОНИ ИМЕЛИ ТЕСНЫЕ РОДСТВЕННЫЕ СВЯЗИ. БОЯРИН ФЕДОР ИВАНОВИЧ ШЕРЕМЕТЕВ (РОД. ОК. 1576 Г.) ЖЕНИЛСЯ ТРИ РАЗА. О ДВУХ ЕГО ЖЕНАХ - ЕФРОСИНЬЕ И МАРИИ ПЕТРОВНЕ НИЧЕГО НЕ ИЗВЕСТНО ${ }^{31}$. В 1613 Г. ШЕРЕМЕТЕВ ЖЕНИЛСЯ НА КНЯЖНЕ ИРИНЕ БОРИСОВНЕ ЧЕРКАССКОЙ (УМ. В 1616 Г.). ${ }^{32}$ ЭТО БЫЛА БЛЕСТЯЩАЯ ПАРТИЯ ДЛЯ ОБОИХ СУПРУГОВ И ПО ЗНАТНОСТИ, И ПО БОГАТСТВУ, И ПО ПОЛОЖЕНИЮ В ОБЩЕСТВЕ. НЕВЕСТА ЯВЛЯЛАСЬ СЕСТРОЙ БОЯРИНА ИВАНА БОРИСОВИЧА ЧЕРКАССКОГО, А ИХ ОБЩЕЙ МАТЕРЬЮ БЫЛА МАРФА (УРОЖД. РОМАНОВА) - РОДНАЯ ТЕТКА ЦАРЯ МИХАИЛА ФЕДОРОВИЧА, СЕСТРА ЕГО ОТЦА, ПАТРИАРХА ФИЛАРЕТА. В СВОЮ ОЧЕРЕДЬ, МАТЬ Ф.И. ШЕРЕМЕТЕВА, АНАСТАСИЯ РОМАНОВНА, ПРИХОДИЛАСЬ РОДНОЙ ТЕТКОЙ ТОМУ ЖЕ ФИЛАРЕТУ. ТАКИМ ОБРАЗОМ, Ф.И. ШЕРЕМЕТЕВА СВЯЗЫВАЛИ ТЕСНЫЕ РОДСТВЕННЫЕ УЗЫ С РОДОМ РОМАНОВЫХ-ЗАХАРЬИНЫХ, И НЕ СЛУЧАЙНО ФЕДОР ИВАНОВИЧ АКТИВНО УЧАСТВОВАЛ В ВЫДВИЖЕНИИ КАНДИДАТУРЫ МИХАИЛА РОМАНОВА НА ПРЕСТОЛ. Ф.И. ШЕРЕМЕТЕВ ИМЕЛ РОДСТВО И С СЕМЬЕЙ ИВАНА ГРОЗНОГО: ЕГО РОДНАЯ СЕСТРА ЕЛЕНА ШЕРЕМЕТЕВА (В МОНАШЕСТВЕ - ЦАРИЦА СТАРИЦА ЛЕОНИДА) БЫЛА ПОСЛЕДНЕЙ ЖЕНОЙ ЦАРЕВИЧА ИВАНА ИВАНОВИЧА, УБИТОГО СВОИМ ОТЦОМ. ЦАРЬ МИХАИЛ ФЕДОРОВИЧ ПОДЧЕРКИВАЛ СВЯЗЬ РОМАНОВЫХ С УГАСШЕЙ ДИНАСТИЕЙ РЮРИКОВИЧЕЙ, ПОЭТОМУ СТАРИЦА ЛЕОНИДА, КАК И АННА КОЛТОВСКАЯ, ПОЛЬЗОВАЛАСЬ ЗАБОТОЙ И УВАЖЕНИЕМ КАК ЧЛЕН СЕМЬИ. СРЕДИ ДУМНЫХ БОЯР В ОПРЕДЕЛЕННЫЙ ПЕРИОД ФЕДОР ИВАНОВИЧ БЫЛ, БЕЗУСЛОВНО, ПЕРВЫМ СРЕДИ РАВНЫХ, А РОД ШЕРЕМЕТЕВЫХ В ЦЕЛОМ - НАИБОЛЕЕ РОДСТВЕННО БЛИЗКИМ ДИНАСТИИ РОМАНОВЫХ.

Ф.И. ШЕРЕМЕТЕВ В 1613 Г. ПО КОЛИЧЕСТВУ ЗЕМЕЛЬ ЗАНИМАЛ ВТОРОЕ МЕСТО СРЕДИ БОЯР (ЗА НИМ ЧИСЛИЛОСЬ 9214 ЧЕТЕЙ ЗЕМЛИ), А КН. И.Б. ЧЕРКАССКИЙ - ПЯТОЕ ${ }^{33}$. КН. И.Б. ЧЕРКАССКИЙ ОКОЛО 1642 Г. УМЕР БЕЗДЕТНЫМ И ЕГО ЗЯТЬ ФЕДОР ИВАНОВИЧ ШЕРЕМЕТЕВ ПОЛУЧИЛ В НАСЛЕДСТВО ЗНАЧИТЕЛЬНУЮ ЧАСТЬ ЕГО ЗЕМЕЛЬ ${ }^{34}$. НАСЛЕДОВАЛ ПОСЛЕ КН. И.Б. ЧЕРКАССКОГО ШЕРЕМЕТЕВ НЕ ТОЛЬКО ЗЕМЛИ, НО И БОЯРСКУЮ СЛУЖБУ: ОКОЛО 20 ЛЕТ ЧЕРКАССКИЙ ЯВЛЯЛСЯ СУДЬЕЙ БЛИЗКИХ ДВОРУ МОСКОВСКИХ ПРИКАЗОВ (БОЛЬШОЙ КАЗНЫ, ИНОЗЕМСКИЙ, СТРЕЛЕЦКИЙ, АПТЕКАРСКИЙ) И ВОЗГЛАВЛЯЛ БОЯРСКУЮ ДУМУ. Ф.И. ШЕРЕМЕТЕВ НАСЛЕДОВАЛ ЭТИ СЛУЖЕБНЫЕ ПОЗИЦИИ, ДОБАВИВ К НИМ НОВУЮ ЧЕТЬ ${ }^{35}$. ФЕДОР ИВАНОВИЧ ИМЕЛ САМЫЙ ВЫСОКИЙ ОКЛАД СРЕДИ БОЯР 700 РУБ., НАРЯДУ С Н.И. РОМАНОВЫМ И КН. И.И. ШУЙСКИМ ${ }^{36}$.

ОДНАКО ПРИ ВСЕМ БЛАГОПОЛУЧИИ СЕМЬИ, СУДЬБА ГРОЗИЛА БОЯРИНУ Ф.И. ШЕРЕМЕТЕВУ ОСТАТЬСЯ БЕЗ НАСЛЕДНИКОВ. ЕГО ЕДИНСТВЕННЫЙ СЫН УМЕР В ОТРОЧЕСТВЕ (В 1632 Г.), ОДНА ИЗ ТРЕХ ДОЧЕРЕЙ (АННА) ПРИНЯЛА ПОСТРИГ, ДРУГАЯ (УЛЬЯНА), БЫВШАЯ В ЗАМУЖЕСТВЕ ЗА БОЯРИНОМ С.В.ГОЛОВИНЫМ, УМЕРЛА В 1652 Г. БЕЗДЕТНОЙ ${ }^{37}$. ОСТАВАЛАСЬ НАСЛЕДНИЦЕЙ ЛИШЬ МЛАДШАЯ ДОЧЬ БОЯРЫНЯ ЕВДОКИЯ ФЕДОРОВНА, ВЫДАННАЯ ЗАМУЖ ЗА КН. НИКИТУ ИВАНОВИЧА ОДОЕВСКОГО. У ЖЕНИХА В РОДУ НЕ ОСТАВАЛОСЬ НИКОГО ПО МУЖСКОЙ ЛИНИИ, ЧТО ОЗНАЧАЛО ПОЛНУЮ КОНЦЕНТРАЦИЮ СЕМЕЙНОЙ СОБСТВЕННОСТИ В ЕГО РУКАХ. ЗА НЕВЕСТОЙ ЖЕ БЫЛО ДАНО ЗНАЧИТЕЛЬНОЕ ПРИДАННОЕ ${ }^{38}$. К МОМЕНТУ СОСТАВЛЕНИЯ Ф.И. ШЕРЕМЕТЕВЫМ В 1645 ГОДУ ЗАВЕЩАНИЯ, ДОЧЬ РОДИЛА ЕМУ ЧЕТЫРЕХ ВНУКОВ - МИХАИЛА, ФЕДОРА, АЛЕКСЕЯ И ЯКОВА, А ТАКЖЕ ВНУЧКУ ПРАСКОВЬЮ. ВСЕ ОНИ, ОДНАКО, НОСИЛИ ФАМИЛИЮ НЕ ШЕРЕМЕТЕВЫХ, А КНЯЗЕЙ ОДОЕВСКИХ. В ТО ЖЕ САМОЕ ВРЕМЯ Ф.И. ШЕРЕМЕТЕВ ИМЕЛ ТРЕХ ТРОЮРОДНЫХ ПЛЕМЯННИКОВ, ДЕТЕЙ БОЯРИНА ПЕТРА НИКИТИЧА ШЕРЕМЕТЕВА, ИВАНА, ВАСИЛИЯ И БОРИСА, КОТОРЫЕ ПОЛАГАЛИ, ЧТО ИМЕННО ОНИ, А НЕ КН. ОДОЕВСКИЕ, ЯВЛЯЮТСЯ 
ПРЯМЫМИ НАСЛЕДНИКАМИ РОДА ШЕРЕМЕТЕВЫХ, И ПОДАВАЛИ ЦАРЮ ЧЕЛОБИТНЫЕ ДЛЯ ЗАЩИТЫ СВОИХ НАСЛЕДСТВЕННЫХ ПРАВ. НО ФЕДОР ИВАНОВИЧ ОТКРЫТО НЕДОЛЮБЛИВАЛ ПЛЕМЯННИКОВ, И ПРИЧИНЫ ЭТОМУ ЛЕЖАЛИ В ЕГО ПРОШЛОМ. В СМУТНОЕ ВРЕМЯ ОН И ЕГО ДВОЮРОДНЫЙ БРАТ ПЕТР НИКИТИЧ ШЕРЕМЕТЕВ ОКАЗАЛИСЬ «ПО РАЗНЫЕ СТОРОНЫ БАРРИКАД». ПЕТР ПОДДЕРЖИВАЛ ГОДУНОВА, А ЗАТЕМ ЛЖЕДИМИТРИЯ І И БЫЛ ЗАДУШЕН В ТЮРЬМЕ ВО ПСКОВЕ ЗА НЕЖЕЛАНИЕ ПРИСЯГНУТЬ ЛЖЕДИМИТРИЮ ІІ. ФЕДОР ЖЕ ГОТОВИЛ ЗАГОВОР ПРОТИВ ГОДУНОВА, БЫЛ СОСЛАН, А ЗАТЕМ ПРИНЯЛ СТОРОНУ ЦАРЯ ВАСИЛИЯ ШУЙСКОГО (И ВЫДАЛ ЗА ЕГО СВОЙСТВЕННИКА ГОЛОВИНА СВОЮ ДОЧЬ УЛЬЯНУ) И СОСТОЯЛ В СЕМИБОЯРЩИНЕ. МЕЖДУ ДВУМЯ ВЕТВЯМИ РОДА ШЕРЕМЕТЕВЫХ ВОЗНИКЛА ПРЯМАЯ ВРАЖДА, И ДАЖЕ НА СТАРОСТИ ЛЕТ БОЯРИН ФЕДОР ИВАНОВИЧ НЕ МОГ ЕЕ ЗАБЫТЬ. ЭТО ОКАЗАЛО ВЛИЯНИЕ НА ЕГО ПРЕДСМЕРТНЫЕ РЕШЕНИЯ.

ВРЕМЯ ПОДВОДИТЬ ИТОГИ ПРИШЛО ДЛЯ Ф.И. ШЕРЕМЕТЕВА В 1645 Г. В ВОЗРАСТЕ 69 ЛЕТ ОН РЕШИЛ ПОКИНУТЬ ДУМУ, ДВОР И СЕМЬЮ И УЙТИ НА ПОКОЙ В КИРИЛЛО-БЕЛОЗЕРСКОЙ МОНАСТЫРЬ, ГДЕ БЫЛ ПОХОРОНЕН ЕГО ЮНЫЙ СЫН И ДРУГИЕ РОДСТВЕННИКИ. В 1649 Г. ПРИНЯВШИЙ ПОСТРИГ Ф.И. ШЕРЕМЕТЕВ «ИЗУСТНО» ДОПОЛНИЛ НАПИСАННОЕ ИМ В 1645 Г. ЗАВЕЩАНИЕ. УМЕР ОН В 1650 Г. В ЭТОТ ЖЕ ПЕРИОД ЗНАЧИМУЮ РОЛЬ В ДУМЕ НАЧАЛ ИГРАТЬ ЕГО ЗЯТЬ БОЯРИН НИКИТА ИВАНОВИЧ ОДОЕВСКИЙ (ПОДРОБНЕЕ СМ. СТАТЬЮ П.В. СЕДОВА В ДАННОМ ИЗДАНИИ). БОЯРИН ФЕДОР ИВАНОВИЧ УМЕЛ РЕШАТЬ ПРОБЛЕМЫ - ЭТО ХОРОШО ДЕМОНСТРИРУЮТ ЕГО РАСПОРЯЖЕНИЯ ПО РАЗДЕЛУ НАСЛЕДСТВА, К КОТОРОМУ ОН ГОТОВИЛСЯ ЗАРАНЕЕ. ПО ЗЕМЕЛЬНОЙ РОСПИСИ 1647 Г. ЗА Ф.И. ШЕРЕМЕТЕВЫМ ЧИСЛИЛСЯ 2791 КРЕСТЬЯНСКИЙ ДВОР В ВОТЧИНАХ И ПОМЕСТЬЯХ ${ }^{39}$. ЕЩЕ ПРИ ЖИЗНИ ОН ПЕРЕПИСАЛ НЕСКОЛЬКО СВОИХ ПОМЕСТИЙ (КОТОРЫЕ КАК ГОСУДАРСТВЕННАЯ СОБСТВЕННОСТЬ НЕ МОГЛИ БЫТЬ ПРЕДМЕТОМ ЗАВЕЩАНИЯ) НА ВНУКОВ. ТАКОВА БЫЛА ОБЫЧНАЯ ПРАКТИКА ПЕРЕДАЧИ ПОТОМСТВУ ПОМЕСТИЙ, НО НЕ ВСЕ ОСУЩЕСТВЛЯЛИ ЕЕ ПРИ ЖИЗНИ. ВЫСЛУЖЕННЫЕ ПОМЕСТЬЯ ШЕРЕМЕТЕВ ВЫКУПАЛ У ГОСУДАРСТВА В ВОТЧИННУЮ СОБСТВЕННОСТЬ И ДЕЛАЛ ИХ, ТАКИМ ОБРАЗОМ, ПРИГОДНЫМИ ДЛЯ ПЕРЕДАЧИ В НАСЛЕДСТВО. ЭТО ТАКЖЕ БЫЛО ОБЫЧНОЙ ПРАКТИКОЙ, ПРИНОСИВШЕЙ ХОРОШИЙ ДОХОД В ГОСУДАРСТВЕННУЮ КАЗНУ. ДЛЯ СВОЕЙ РОДНОЙ СЕМЬИ (ДОЧЕРИ, ЗЯТЯ, ИХ ДЕТЕЙ И ВНУКОВ) ФЕДОР ИВАНОВИЧ ПОШЕЛ НА ТО, ЧТОБЫ ИЗЪЯТЬ СВОИ ЗЕМЛИ ИЗ РОДА ШЕРЕМЕТЕВЫХ, А ЭТО БЫЛО ВОПИЮЩИМ ПОСТУПКОМ, ОСОБЕННО ДЛЯ ЕГО ПЛЕМЯННИКОВ «ПЕТРОВИЧЕЙ». ПОЛНОСТЬЮ ЛИШИТЬ НАСЛЕДСТВА ПРЕДСТАВИТЕЛЕЙ МУЖСКОЙ ЛИНИИ РОДА ШЕРЕМЕТЕВЫХ («ПЕТРОВИЧЕЙ») БЫЛО ПРОТИВНО ЗАКОНАМ И ОБЫЧАЯМ, НО ОПЫТНЫЙ БОЯРИН ЗНАЛ, КАК ОБХОДИТЬ ЗАКОНЫ. ОН ПОПРОСИЛ ЦАРЯ МИХАИЛА ФЕДОРОВИЧА, ЕГО СВОЙСТВЕННИКА ПО ЖЕНЕ, БЫТЬ ЕГО ДУШЕПРИКАЗЧИКОМ, ЗА ЧТО (КАК ОБЫЧНО ДЕЛАЛОСЬ В БЛАГОДАРНОСТЬ ЗА ХЛОПОТЫ ДУШЕПРИКАЗЧИКОВ) ОТДАЛ ЕМУ СВОЮ ОГРОМНУЮ СОКОЛЬСКУЮ ВОЛОСТЬ В ЮРЬЕВЕ ПОВОЛЬСКОМ, В КОТОРОЙ ИМЕЛОСЬ 1072 КРЕСТЬЯНСКИХ ДВОРА. ЕСТЕСТВЕННО, ЦАРЬ НЕ МОГ В РЕАЛЬНОСТИ ИСПОЛНЯТЬ ОБРЕМЕНИТЕЛЬНУЮ РОЛЬ ДУШЕПРИКАЗЧИКА, ЕЕ ИСПОЛНЯЛ ЗЯТЬ, КН. НИКИТА ИВАНОВИЧ ОДОЕВСКИЙ, НО ЦАРЮ КАК ДУШЕПРИКАЗЧИКУ СЛЕДОВАЛО ЕГО КОНТРОЛИРОВАТЬ. ДАЛЕЕ ФЕДОР ИВАНОВИЧ ПРОСИЛ СПЕЦИАЛЬНОГО РАЗРЕШЕНИЯ ЦАРЯ ПЕРЕДАТЬ СВОЕ С. МЕЛЕНКИ С ДЕРЕВНЯМИ В КИРИЛЛО-БЕЛОЗЕРСКИЙ МОНАСТЫРЬ, НАРУШАЯ ТЕМ САМЫМ ЦАРСКИЕ УКАЗЫ О ЗАПРЕТЕ ПЕРЕДАЧИ ЗЕМЕЛЬ В МОНАСТЫРИ. НО ПОЛНОСТЬЮ ЛИШИТЬ НАСЛЕДСТВА ПЛЕМЯННИКОВ, КОТОРЫЕ УЖЕ ЗАРАНЕЕ ГОТОВИЛИСЬ ОСПАРИВАТЬ ЗАВЕЩАНИЕ ФЕДОРА ИВАНОВИЧА ${ }^{40}$, ВСЕ ЖЕ НЕ УДАЛОСЬ: ТАКОЕ НАРУШЕНИЕ 
ТРАДИЦИИ ПЕРЕДАЧИ РОДОВЫХ ЗЕМЕЛЬ ПО МУЖСКОЙ ЛИНИИ БЫЛО БЫ ИЗ РЯДА ВОН ВЫХОДЯЩИМ. «ПЕТРОВИЧАМ» - ИВАНУ, ВАСИЛИЮ И БОРИСУ ДОСТАЛИСЬ-ТАКИ 105 ДВОРОВ ВО ВЛАДИМИРСКОМ УЕЗДЕ, 71 ДВОР В КОЛОМЕНСКОМ, 183 ДВОРА В РЯЗАНСКОМ И ПОДМОСКОВНОЕ СЕЛЬЦО КУСКОВО (В ОБЩЕЙ СЛОЖНОСТИ ОКОЛО 360 ДВОРОВ $)^{41}$.

ВСЕ ОСТАЛЬНЫЕ ЗЕМЛИ, В КОТОРЫХ НАСЧИТЫВАЛОСЬ 1379 ДВОРОВ, ФЕДОР ИВАНОВИЧ ПЕРЕДАЛ В СЕМЬЮ ДОЧЕРИ ЕВДОКИИ. НО И ВНУТРИ СЕМЬИ РАСПРЕДЕЛЕНИЕ НАСЛЕДСТВА ДАЛЕКО НЕ НОСИЛО УРАВНИТЕЛЬНОГО ХАРАКТЕРА. ОСНОВНУЮ НАСЛЕДСТВЕННУЮ МАССУ БОЯРИН ПЛАНИРОВАЛ СКОНЦЕНТРИРОВАТЬ В РУКАХ ОДНОГО НАСЛЕДНИКА, ХОТЯ ОСТАЛЬНЫХ ТОЖЕ СТАРАЛСЯ КАК-ТО ОБЕСПЕЧИТЬ. ДОЧЬ ПОЛУЧИЛА КОСТРОМСКУЮ ВОТЧИНУ С 319 ДВОРАМИ. КАК УЖЕ ГОВОРИЛОСЬ, В 1645 Г. ЗА ДОСТИГНУВШИМИ СОВЕРШЕННОЛЕТИЯ ВНУКАМИ МИХАИЛОМ И ФЕДОРОМ БЫЛИ ЗАПИСАНЫ ПО ПРОСЬБЕ ДЕДА ВСЕ ЕГО ПОМЕСТНЫЕ ЗЕМЛИ В ГАЛИЦКОМ У., 517 ДВОРОВ БЕЗ РАЗДЕЛА, А ВНУЧКА ПРАСКОВЬЯ В 1647 Г. БЫЛА ВЫДАНА ЗАМУЖ ЗА ГРИГОРИЯ СУНЧАЛЕЕВИЧА ЧЕРКАССКОГО И ПОЛУЧИЛА ПРИДАНОЕ. ПО ЗАВЕЩАНИЮ ЖЕ МИХАИЛ, ФЕДОР И ПРАСКОВЬЯ ОДОЕВСКИЕ НАСЛЕДОВАЛИ НЕМНОГО - В ОБЩЕЙ СЛОЖНОСТИ 162 ДВОРА. НО ДАЖЕ И НА ЭТИ НЕМНОГОЧИСЛЕННЫЕ ДВОРЫ Ф.И. ШЕРЕМЕТЕВ НАЛОЖИЛ ПРАВО СУБСТИТУЦИИ: ВНУКИ НЕ МОГЛИ ПЕРЕДАВАТЬ ИХ СВОИМ ДЕТЯМ ПОСЛЕ СМЕРТИ, НО ТОЛЬКО МАТЕРИ ИЛИ БРАТЬЯМ. ОСТАЛЬНЫЕ ВОТЧИНЫ, ИМЕВШИЕ 1217 КРЕСТЬЯНСКИХ ДВОРОВ, А ТАКЖЕ МОСКОВСКИЕ УСАДЬБЫ, В ТОМ ЧИСЛЕ КРЕМЛЕВСКАЯ, ДОСТАВАЛИСЬ МЛАДШЕМУ ВНУКУ ЯКОВУ, БЕЗ ВСЯКИХ СУБСТИТУЦИОНАЛЬНЫХ ОГРАНИЧЕНИЙ ${ }^{42}$. ПОЧЕМУ ТАК? ШЕРЕМЕТЕВ ЭТОГО В ЗАВЕЩАНИИ НЕ ОБЪЯСНЯЕТ, НО МОЖНО ДОГАДАТЬСЯ, ЧТО ЯКОВУ В ЭТО ВРЕМЯ БЫЛО СОВСЕМ МАЛО ЛЕТ И ФАКТИЧЕСКИ ЕГО ЗЕМЛЯМИ РАСПОРЯЖАЛИСЬ РОДИТЕЛИ, БОЛЕЕ БЛАГОРАЗУМНЫЕ, ЧЕМ МОЛОДЕЖЬ. ТАКИМ ОБРАЗОМ, МЛАДШИЙ СЫН ЯКОВ В СЕМЬЕ ОДОЕВСКИХ К СЕРЕДИНЕ ХVII В. СТАЛ САМЫМ БОГАТЫМ ЕЕ ЧЛЕНОМ, БЛАГОДАРЯ ДЕДУ. ПОЗДНЕЕ ЯКОВ НИКИТИЧ ПОЛУЧИЛ СОЛИДНУЮ ВОТЧИНУ ПО ЗАВЕЩАНИЮ МАТЕРИ, ПОСТРИГШЕЙСЯ В МОНАСТЫРЬ В $1671 \Gamma^{43}$, А ТАКЖЕ 1800 ДВОРОВ ПО ЗАВЕЩАНИЮ ОТЦА. К 1696 Г. ЗА НИМ ЧИСЛИЛОСЬ 2185 ДВОРОВ ${ }^{44}$. ИЗ ЗАВЕЩАНИЯ МАТЕРИ ЯКОВА, ТЕМ НЕ МЕНЕЕ, ПОНЯТНО, ЧТО ОНА ИЗЪЯВИЛА НЕ СВОЕ ЖЕЛАНИЕ, А ВЫПОЛНИЛА ВОЛЮ ОТЦА, ХОТЕВШЕГО, ЧТОБЫ ЕЕ ЗЕМЛИ ТОЖЕ ОТОШЛИ К ЯКОВУ. ВОЛЯ Ф.И.ШЕРЕМЕТЕВА ОКАЗАЛАСЬ ПРОВИДЧЕСКОЙ: ЕГО СТАРШИЕ ВНУКИ МИХАИЛ, ФЕДОР И АЛЕКСЕЙ РАНО УМЕРЛИ, А МЛАДШИЙ ЯКОВ ПРОЖИЛ ДОЛГУЮ ЖИЗНЬ (УМ. В 1697 Г.). ОДНАКО, ПО ИРОНИИ СУДЬБЫ, ЕГО СТАРШИЕ БРАТЬЯ УСПЕЛИ ЖЕНИТЬСЯ И РОДИТЬ СЫНОВЕЙ, ТОГДА КАК У ЯКОВА БЫЛИ ТОЛЬКО ДОЧЕРИ. ОТСУТСТВИЕ МУЖСКОГО ПОТОМСТВА В ЕГО СЕМЬЕ ОЗНАЧАЛО ПЕРСПЕКТИВУ НОВОГО ПЕРЕХОДА БОЛЬШЕЙ ЧАСТИ «ШЕРЕМЕТЕВСКО-ОДОЕВСКОГО» НАСЛЕДСТВА В ДРУГОЙ РОД.

ГЛАВА СЕМЬИ КН. НИКИТА ИВАНОВИЧ НАМНОГО ПЕРЕЖИЛ ВСЕХ СВОИХ ДЕТЕЙ, КРОМЕ МЛАДШЕГО ЯКОВА, И НЕКОТОРЫХ ВНУКОВ. ЕГО СЕМЬЯ БЫЛА БОЛЬШОЙ И МНОГОПОКОЛЕННОЙ, ПОЭТОМУ ЗАВЕЩАНИЕ БЫЛО СОСТАВИТЬ НЕЛЕГКО, И ОНО ОКАЗАЛОСЬ ОЧЕНЬ ПРОСТРАННЫМ ${ }^{45}$. ПРЕДСТАВЛЯЕТСЯ, ЧТО КН. НИКИТА ИВАНОВИЧ ВЗЯЛ СЕБЕ ЗА ОБРАЗЕЦ ЗАВЕЩАНИЕ СВОЕГО ТЕСТЯ ШЕРЕМЕТЕВА. СЫНУ ЯКОВУ, КАК УЖЕ ГОВОРИЛОСЬ, ОН ЗАВЕЩАЛ МНОГО - 1800 ДВОРОВ, НО ВСЕ ЖЕ БОЛЬШУЮ ЧАСТЬ НАСЛЕДСТВА ОСТАВИЛ ПРАВНУКУ, ПОТОМКУ СВОЕГО СТАРШЕГО СЫНА МИХАИЛА, ЮРИЮ ЮРЬЕВИЧУ, И ГОРАЗДО МЕНЬШЕ - ЕГО БРАТУ МИХАИЛУ ЮРЬЕВИЧУ. «ПРАВНУКА СВОЕГО, ЮРИЯ ЮРЬЕВИЧА [РОД. 1672 Г.] ВЗЯЛ ЯЗ У ОТЦА ЕВО [УМ. В 1685 Г. - О.К] [...] ЗА СЫНА МЕСТО ШТИ ЛЕТ, ВСКОРМИЛ ЕВО И ВЫУЧИЛ» ${ }^{46},-$ ПИСАЛ КН. НИКИТА ИВАНОВИЧ. НО 
ИСТОРИЯ НЕ ПОВТОРИЛАСЬ: ЮРИЙ ЮРЬЕВИЧ, В ОТЛИЧИЕ ОТ ЯКОВА НИКИТИЧА, НЕ ОПРАВДАЛ НАДЕЖД ДЕДА. ОН УМЕР В ВОЗРАСТЕ 50 ЛЕТ, НЕ ОСТАВИВ НАСЛЕДНИКОВ. СОХРАНИЛИСЬ СВИДЕТЕЛЬСТВА ТОГО, КАК ЗА ГОД ДО СМЕРТИ ГЕНЕРАЛ-АДЪЮТАНТ КН. Ю.Ю. ОДОЕВСКИЙ РАССТАВАЛСЯ С ДЕДОВЫМ РОДОВЫМ НАСЛЕДСТВОМ. В 1721 Г. ОН ЗАЛОЖИЛ ЗЕМЛИ В ШАЦКОМ У. В ЦЕНСКОМ СТАНЕ С.АЛЕШНИ С ПУСТОШАМИ И ПОКОСАМИ ПОДПОЛКОВНИКУ НИКИТЕ АФАНАСЬЕВИЧУ КОЗЛОВУ. СОСЕДНЮЮ ВОТЧИНУ В ТОМ ЖЕ ЦЕНСКОМ И ПОЛЕССКОМ СТАНАХ С. ЗИМЕНКИ С ПУСТОШАМИ И ПОКОСАМИ И СО ВСЕМИ КРЕСТЬЯНАМИ И БОБЫЛЯМИ ОН ЗАЛОЖИЛ БРАТЬЯМ ЧЕБЫШЕВЫМ ЗА 5 ТЫС. РУБ. В С. ЗИМЕНКИ БЫЛ БОЯРСКИЙ ДВОР, ВОЗМОЖНО, ЕЩЕ ДЕДОВ, ПРИКАЗНАЯ ИЗБА С «ДЕЛОВЫМИ ЛЮДЬМИ» (Т.Е. УПРАВЛЯЮЩИМИ ХОЗЯЙСТВОМ), КОННЫЙ ЗАВОД, СКОТНЫЙ ДВОР, МЕЛЬНИЦА НА Р. АЛЕШНЕ «СО ВСЯКИМ МЕЛНИШНЫМ СТРОЕНИЕМ И ЗАВОДОМ». ПАШНИ В С.ЗИМЕНКАХ БЫЛО 1170 ЧЕТЕЙ С ОСМИНОЮ, СЕННЫХ ПОКОСОВ НА 2 ТЫС. КОПЕН, И ЛЕСУ, И ДУБРАВ, И БОЛОТА 282 ДЕСЯТИНЫ. ПО Р. ЦНЕ ИМЕНИЮ ПРИНАДЛЕЖАЛИ 10 ВЕРСТ РЫБНЫХ ЛОВЕЛЬ, А ТАКЖЕ 11 ОЗЕР С КЛЮЧАМИ И С «РОСЧИСТНЫМИ ЗЕМЛЯМИ». ПРИ БОЯРИНЕ НИКИТЕ ИВАНОВИЧЕ В 1678 Г. В СЕЛЕ ЧИСЛИЛОСЬ 290 КРЕСТЬЯНСКИХ ДВОРОВ. К 1721 Г. ДВОРОВ МЕНЬШЕ НЕ СТАЛО ${ }^{47}$. КРЕДИТОРЫ КН. ЮРИЯ ЮРЬЕВИЧА ЖАЛОВАЛИСЬ В СУД, ЧТО ОН ТАЙНО ВЫВОДИТ КРЕСТЬЯН И ЛОШАДЕЙ ИЗ ЗАКЛАДНЫХ ЗЕМЕЛЬ В СВОИ ДМИТРОВСКИЕ ВОТЧИНЫ. ПОЭТОМУ ИЗ ШАЦКОГО СУДА ПОЕХАЛИ ПРИКАЗЧИКИ ВСЕ ИМЕНИЕ ПЕРЕПИСЫВАТЬ И ЛЮДЕЙ ПОДСЧИТЫВАТЬ ${ }^{48}$. В ТОМ ЖЕ 1721 Г. КН. ЮРИЙ ЮРЬЕВИЧ ЗАЛОЖИЛ РОДОВОЕ ПОДМОСКОВНОЕ ИМЕНИЕ НИКОЛО-УРЮПИНО КН.С.Г. ДОЛГОРУКОМУ. ВИДИМО, ЮРИЙ ЗАКЛАДЫВАЛ ВСЕ РОДОВЫЕ ВОТЧИНЫ, СОБИРАЯ ДЕНЬГИ СЕБЕ НА ПОМИНОВЕНИЕ В МОНАСТЫРЯХ, ПЕРЕД НАСТИГШЕЙ ЕГО В 1722 Г. СМЕРТЬЮ.

КАК СЛОЖИЛИСЬ БРАЧНЫЕ УЗЫ И СЕМЕЙНАЯ ЖИЗНЬ ПОТОМКОВ НИКИТЫ ИВАНОВИЧА ОДОЕВСКОГО? СТАРШИЙ СЫН, КН. МИХАИЛ НИКИТИЧ, УЧАСТВУЯ В 1652 Г. В ОДНОЙ ИЗ ЦАРСКИХ ОХОТ, ЗАБОЛЕЛ И УМЕР. ПОДРОБНОСТИ ЕГО СМЕРТИ МЫ ЗНАЕМ ИЗ ЗАМЕЧАТЕЛЬНОГО ПИСЬМА ЦАРЯ АЛЕКСЕЯ МИХАЙЛОВИЧА, КОТОРЫЙ ЛИЧНО НАПИСАЛ О ГОРЬКОЙ ВЕСТИ ЕГО ОТЦУ ${ }^{49}$. ЦАРЬ ПРЕДЛАГАЛ БОЯРИНУ ДЕНЕЖНУЮ ПОМОЩЬ НА ПОХОРОНЫ СЫНА, ИЗ ЧЕГО С.М. СОЛОВЬЕВ СДЕЛАЛ ОШИБОЧНЫЙ ВЫВОД, ЧТО СЕМЬЯ ОДОЕВСКИХ «БЫЛА НЕБОГАТАЯ» ${ }^{50}$ ВСЕ ПРОЧИЕ ДОКУМЕНТЫ СВИДЕТЕЛЬСТВУЮТ ОБ ОБРАТНОМ - СЕМЬЯ БЫЛА БОГАТЕЙШЕЙ.

ПО СМЕРТИ КН. МИХАИЛА ОСТАЛСЯ ЕГО СЫН КН. ЮРИЙ МИХАЙЛОВИЧ (УМ. 1685), СТАВШИЙ, КАК И ВСЕ КНЯЗЬЯ ОДОЕВСКИЕ, ДУМНЫМ БОЯРИНОМ. ВНУЧКИ МИХАИЛА ЕВДОКИЯ И АННА - БЫЛИ ВЫДАНЫ ЗАМУЖ В ПРОЦВЕТАЮЩУЮ СЕМЬЮ КНЯЗЕЙ ДОЛГОРУКИХ; О ЖЕНИТЬБЕ 4 ВНУКОВ (АЛЕКСЕЕ, ВАСИЛИИ, МИХАИЛЕ И ЮРИИ) ИЗВЕСТНО ТОЛЬКО, ЧТО КН. ВАСИЛИЙ БЫЛ ЖЕНАТ НА МАРИИ АЛЕКСЕЕВНЕ, УРОЖД. КНЯЖНЕ ЛЫКОВОЙ-ОБОЛЕНСКОЙ.

ДРУГОЙ СЫН КН. НИКИТЫ ИВАНОВИЧА ОДОЕВСКОГО, КН. АЛЕКСЕЙ НИКИТИЧ, (УМ. 1655 Г.) БЫЛ ЖЕНАТ НА КНЯЖНЕ УЛЬЯНЕ ИВАНОВНЕ ГОЛИЦЫНОЙ. ДОЧЬ ФЕОДОСИЮ ОНИ ВЫДАЛИ ЗА КН. И.Г. КУРАКИНА.

ИМЯ ЖЕНЫ ТРЕТЬЕГО СЫНА КН. НИКИТЫ ИВАНОВИЧА ОДОЕВСКОГО КН. ФЕДОРА НИКИТИЧА (УМ. В 1656 Г.) НЕИЗВЕСТНО. ОН ИМЕЛ СЫНОВЕЙ СТЕПАНА (УМ. 1666 Г.) И ВАСИЛИЯ (УМ. 1686 Г.), ЖЕНАТОГО НА АКУЛИНЕ ФЕДОРОВНЕ РТИЩЕВОЙ. ДОЧЬ НИКИТЫ ИВАНОВИЧА ОДОЕВСКОГО ПРАСКОВЬЯ (УМ. 1656 Г.), КАК УЖЕ ГОВОРИЛОСЬ, СОСТОЯЛА В БРАКЕ С КН. Г.С. ЧЕРКАССКИМ. ИХ ЕДИНСТВЕННЫЙ СЫН ДАНИИЛ (УМ. 1706) 
ЖЕНИЛСЯ НА МАРИИ ПЕТРОВНЕ ШЕРЕМЕТЕВОЙ (1668-1737), РОДНОЙ СЕСТРЕ ФЕЛЬДМАРШАЛА, ДОЧЕРИ БОЯРИНА ПЕТРА ВАСИЛЬЕВИЧА БОЛЬШОГО ШЕРЕМЕТЕВА И АННЫ ФЕДОРОВНЫ ВОЛЫНСКОЙ. ТАКИМ ОБРАЗОМ, ПОТОМКИ «ПЕТРОВИЧЕЙ» ШЕРЕМЕТЕВЫХ ЧЕРЕЗ ПОКОЛЕНИЕ ВНОВЬ СОЕДИНИЛИСЬ С ДАЛЬНИМИ РОДСТВЕННИКАМИ СТОЛЬ ВРАЖДЕБНОГО К НИМ ФЕДОРА ИВАНОВИЧА ШЕРЕМЕТЕВА. ИХ ДОЧЬ - ЕЛЕНА ЧЕРКАССКАЯ - В 1692 Г. ВЫШЛА ЗАМУЖ ЗА КН. Ю.Ю. ТРУБЕЦКОГО. С НЕЙ МЫ ЕЩЕ ВСТРЕТИМСЯ НИЖЕ. ДОЧЕРИ ЯКОВА НИКИТИЧА ОДОЕВСКОГО ${ }^{51}$ - МАРФА, АННА И ДОМНА. О МЛАДШЕЙ ПРАКТИЧЕСКИ НИЧЕГО НЕ ИЗВЕСТНО. СРЕДНЯЯ СЕСТРА КНЯЖНА АННА ЯКОВЛЕВНА (УМ. 1750) ВЫШЛА ЗАМУЖ В 1684 Г. ЗА КН. Д.М. ГОЛИЦЫНА - ИЗВЕСТНЕЙШЕГО ПОЛИТИЧЕСКОГО ДЕЯТЕЛЯ ПЕРВОЙ ПОЛОВИНЫ XVIII В. СТОЛЕТИЯ. В ИХ СЕМЬЕ РОДИЛИСЬ И ПРОЖИЛИ ДОЛГУЮ ЖИЗНЬ ДОчь И ДВА СЫНА.

СТАРШАЯ ИЗ ДОЧЕРЕЙ, КНЯЖНА МАРФА ЯКОВЛЕВНА, БЫЛА ВЫДАНА В 1667 Г. ЗАМУЖ ЗА МОЛОДОГО КН. МИХАИЛА ЯКОВЛЕВИЧА ЧЕРКАССКОГО, ЕДИНСТВЕННОГО СЫНА КН. ЯКОВА КУДЕНЕТОВИЧА ЧЕРКАССКОГО, АККУМУЛИРОВАВШЕГО К ЭТОМУ ВРЕМЕНИ БОЛЬШУЮ ЧАСТЬ ЗЕМЕЛЬ КН. ЧЕРКАССКИХ, НАХОДИВШИХСЯ НА МОСКОВСКОЙ СЛУЖБЕ ${ }^{52}$. ЯКОВОМ КУДЕНЕТОВИЧЕМ БЫЛА ПРИОБРЕТЕНА 21 ВОТЧИНА (9 935 ДЕСЯТИН ЗЕМЛИ) НА СУММУ В 3994 РУБ. ПО ЗЕМЕЛЬНОЙ РОСПИСИ 1647 Г. КН. Я.К. ЧЕРКАССКИЙ ИМЕЛ 5173 ДВОРА (Т.Е. ЗНАЧИТЕЛЬНО БОЛЬШЕ, ЧЕМ Ф.И. ШЕРЕМЕТЕВ), А В 1653 Г. ЗА НИМ ЗНАЧИЛОСЬ 6790 КРЕСТЬЯНСКИХ ДВОРОВ ${ }^{53}$. ТАКИМ ОБРАЗОМ, ЕДИНСТВЕННЫЙ СЫН МИХАИЛ ЯКОВЛЕВИЧ БЫЛ ОЧЕНЬ ВЫГОДНЫМ ЖЕНИХОМ, КАК РАЗ ПОД СТАТЬ БОГАТОЙ НЕВЕСТЕ МАРФЕ ОДОЕВСКОЙ. ЗА МАРФОЙ В ПРИДАНОЕ БЫЛА ОТДАНА РОДОВАЯ ВОТЧИНА ОДОЕВСКИХ ПОДМОСКОВНОЕ АРХАНГЕЛЬСКОЕ. ПОСЛЕ ЕЕ СМЕРТИ ОНО ПЕРЕШЛО К ЕЕ СЕСТРЕ АННЕ ГОЛИЦЫНОЙ ${ }^{54}$. В 1680 Г. КАРЬЕРА М.Я. ЧЕРКАССКОГО НАЧАЛА ПРОДВИГАТЬСЯ: ОН БЫЛ НАЗНАЧЕН СТОЛЬНИКОМ К СЕМИЛЕТНЕМУ ЦАРЕВИЧУ ПЕТРУ, А В 1682 Г. СТАЛ БОЯРИНОМ В ДУМЕ 55 . В СЕМЬЕ РОДИЛОСЬ ЧЕТЫРЕ ДОЧЕРИ И ДВА СЫНА (ПЕТР И АЛЕКСЕЙ). МАЛЬЧИКИ 28 АПРЕЛЯ 1688 Г. БЫЛИ ПОЖАЛОВАНЫ В СПАЛЬНИКИ К СТАРШЕМУ БРАТУ ЦАРЯ ПЕТРА АЛЕКСЕЕВИЧА (1672-1725) ЦАРЮ ИОАННУ АЛЕКСЕЕВИЧУ (1666-1696) ${ }^{56}$. НАЗНАЧЕНИЕ ЭТО БЫЛО ОЧЕНЬ ПОЧЕТНЫМ. ОБОИХ ДЕТЕЙ ВОСПИТЫВАЛ ХОРОШО ОБРАЗОВАННЫЙ И СТАРАТЕЛЬНЫЙ УЧИТЕЛЬ ${ }^{57}$. В 1693 Г. БРАТЬЯ БЫЛИ ПЕРЕВЕДЕНЫ В СПАЛЬНИКИ 20-ЛЕТНЕГО ЦАРЯ ПЕТРА АЛЕКСЕЕВИЧА. В БУДУЩЕМ ИМ ПРЕДСТОЯЛО ВСЛЕД ЗА ОТЦОМ СТАТЬ ДУМНЫМИ БОЯРАМИ, НО ИХ ВРЕМЯ ВЫПАЛО НА ЦАРСТВОВАНИЕ ПЕТРА, КОГДА В БОЯРСКИЕ ЧИНЫ УЖЕ ПОЧТИ НЕ ЖАЛОВАЛИ. В 1697 Г. М.Я. ЧЕРКАССКИЙ БЫЛ НАЗНАЧЕН СИБИРСКИМ ВОЕВОДОЙ И УЕХАЛ В ТОБОЛЬСК СО ВСЕЙ СЕМЬЕЙ. В 1699 Г. ЕГО СТАРШИЙ СЫН КН. ПЕТР, КАПИТАН ПРЕОБРАЖЕНСКОГО ПОЛКА, СТАЛ ПОМОЩНИКОМ ОТЦА НА ВОЕВОДСТВЕ, К ЭТОМУ ВРЕМЕНИ ОН УЖЕ БЫЛ ЖЕНАТ НА МАРФЕ БОРИСОВНЕ ГОЛИЦЫНОЙ. В ЭТОМ ЖЕ 1699 ГОДУ СКОНЧАЛАСЬ МАТЬ БРАТЬЕВ, А В 1701 Г. УШЕЛ ИЗ ЖИЗНИ КН. ПЕТР, ОСТАВИВ ГОДОВАЛУЮ ДОЧЬ МАРФУ. ЧЕРКАССКИЕ ВЕРНУЛИСЬ В МОСКВУ В 1710 Г., И КН. МИХАИЛ ЯКОВЛЕВИЧ ВСКОРЕ УМЕР, А ЕГО МЛАДШИЙ СЫН КН. АЛЕКСЕЙ, В БУДУЩЕМ ИЗВЕСТНЫЙ ПОЛИТИЧЕСКИЙ ДЕЯТЕЛЬ ПЕРВОЙ ПОЛОВИНЫ XVIII В. ${ }^{58}$, СТАЛ ЕДИНСТВЕННЫМ НАСЛЕДНИКОМ СВОЕГО ОЧЕНЬ СОСТОЯТЕЛЬНОГО ОТЦА. ПЕРВЫМ, ОСТАВШИМСЯ БЕЗДЕТНЫМ, БРАКОМ КН. АЛЕКСЕЙ МИХАЙЛОВИЧ БЫЛ ЖЕНАТ НА ДВОЮРОДНОЙ СЕСТРЕ ЦАРЯ ПЕТРА АННЕ ЛЬВОВНЕ НАРЫШКИНОЙ. В ВОЗРАСТЕ ОКОЛО 40 ЛЕТ ${ }^{59}$ КНЯЗЬ СОЧЕТАЛСЯ ВТОРЫМ БРАКОМ С 16-ЛЕТНЕЙ КНЯЖНОЙ МАРЬЕЙ ЮРЬЕВНОЙ ТРУБЕЦКОЙ - ДОЧЕРЬЮ КН. ЮРИЯ ЮРЬЕВИЧА ТРУБЕЦКОГО (1668-1639) И ВЫШЕУПОМЯНУТОЙ КНЯГИНИ ЕЛЕНЫ ГРИГОРЬЕВНЫ ЧЕРКАССКОЙ, Т.Е. РОДНОЙ ВНУЧКОЙ 
ПРАСКОВЬИ НИКИТИЧНЫ ОДОЕВСКОЙ (ТАКИМ ОБРАЗОМ, МАТЬ А.М. ЧЕРКАССКОГО ПРИХОДИЛАСЬ ЕГО ЖЕНЕ ДВОЮРОДНОЙ ТЕТКОЙ, Т.Е. ОН ЖЕНИЛСЯ НА ТРОЮРОДНОЙ СЕСТРЕ).

СЕМЕЙНАЯ СИТУАЦИЯ ЧЕТЫ КН. А.М. ЧЕРКАССКОГО И КН. МАРИИ ТРУБЕЦКОЙ ОКАЗАЛАСЬ СХОЖЕЙ С ИСТОРИЕЙ СЕМЬИ ЕГО МАТЕРИ, УРОЖДЕННОЙ МАРФЫ ЯКОВЛЕВНЫ ОДОЕВСКОЙ - У ВЛАДЕЛЬЦА БОГАТЕЙШЕГО СОСТОЯНИЯ РОДИЛАСЬ ЕДИНСТВЕННАЯ ДОЧЬ-НАСЛЕДНИЦА - КНЯЖНА ВАРВАРА АЛЕКСЕЕВНА ЧЕРКАССКАЯ. В ПЕРЕПИСИ 1718 Г. СЕМЬЯ КН. А.М. ЧЕРКАССКОГО ПРЕДСТАВЛЕНА ТАК: «ЖЕНА ЕВО МАРЬЯ 23 ГОДА, СЕСТРА АННА 22 ГОДА, ДОЧЬ ВАРВАРА - 6 ЛЕТ ${ }^{60}$. ПЕТЕРБУРГСКИЙ ДОМ, В КОТОРОМ ЖИЛА МАЛЕНЬКАЯ ВАРВАРА, БЫЛ ОДНИМ ИЗ ЛУЧШИХ:

НИЖНИХ 12 СВЕТЛИЦ, 7 ПЕЧЕЙ, ВЕРХНИХ 15 СВЕТЛИЦ, В ТОМ ЧИСЛЕ ОДНА ПЕЧЬ КУХАРНАЯ, С ПЕЧЬЮ БАНЯ, С ПЕЧЬЮ ЧЕТЫРЕ СЕНИ, ИЗБА СУДОВАЯ [sic!] С ПЕЧЬЮ, ПОВАРНЯ, В НЕЙ ДВА ОЧАГА, ДВЕ ИЗБЫ ХЛЕБНЫЯ, ДА БАСМАННАЯ, В НИХ ПО ДВЕ ПЕЧИ, МЕЖДУ НИМИ СЕНИ, ШЕСТЬ ИЗБ ЛЮДЦКИХ С ПЕЧМИ, ТРИ ПОГРЕБА С НАПОГРЕБЦАМИ, В ТОМ ЧИСЛЕ ОДИН ЛЕДНИК, ТРИ АНБАРА ЗАПАСНЫХ, КОНЮШНЯ, ИЗБА ВЕТХАЯ БЕЗ ПЕЧИ, НА ЗАДНЕМ ДВОРЕ МШЕНИК ДЛЯ СКОТА. ${ }^{6}$

Я НАЧАЛА С ТОГО, ЧТО КН. ВАРВАРА АЛЕКСЕЕВНА ЧЕРКАССКАЯ В 1743 Г. ВЫШЛА ЗАМУЖ ЗА ПЕТРА БОРИСОВИЧА ШЕРЕМЕТЕВА И ОНИ СТАЛИ САМОЙ БОГАТОЙ СЕМЬЕЙ РОССИИ. ПРОСЛЕДИВ ПРЕДШЕСТВОВАВШУЮ ЭТОМУ СОБЫТИЮ ПОЛУТОРАСТОЛЕТНЮЮ СЕМЕЙНУЮ ИСТОРИЮ, МЫ ВИДИМ, ЧТО ОНА ПРИВЕЛА К ТОМУ, С ЧЕГО НАЧАЛАСЬ: К СОЕДИНЕНИЮ В БРАКЕ ПРЕДСТАВИТЕЛЕЙ РОДОВ БОЯР ШЕРЕМЕТЕВЫХ И КНЯЗЕЙ ЧЕРКАССКИХ. ОДНАКО, КАК УЖЕ ГОВОРИЛОСЬ, РОД ШЕРЕМЕТЕВЫХ ПО МУЖСКОЙ ЛИНИИ ПРОДОЛЖИЛСЯ ВНЕ ЭТОЙ ИСТОРИИ, НЕ ЧЕРЕЗ ПОТОМСТВО ФЕДОРА ИВАНОВИЧА, СТАВШЕГО КНЯЗЬЯМИ ОДОЕВСКИМИ, А ЧЕРЕЗ ПОТОМСТВО ПЕТРА НИКИТИЧА, ЧЕРЕЗ «ПЕТРОВИЧЕЙ». И ЖЕНИХ В ЭТОЙ ПАРЕ ПРЕДСТАВЛЯЛ ИМЕННО ЭТУ ВЕТВЬ ШЕРЕМЕТЕВЫХ. НА ЕЕ СЕМЕЙНОЙ ИСТОРИИ Я ОСТАНОВЛЮСЬ НИЖЕ.

ВОЗМОЖНО ЛИ ГОВОРИТЬ О «КЛАНЕ» ШЕРЕМЕТЕВЫХ-ОДОЕВСКИХ-ЧЕРКАССКИХ? ИЗУЧАЯ БОЯРСТВО XVII В., РОБЕРТ КРАММИ ТАКЖЕ НЕ МОГ ПРОЙТИ МИМО МАТЕРИАЛОВ АРХИВА ШЕРЕМЕТЕВЫХ И НЕ ОСТАНОВИТЬСЯ НА ИСТОРИИ РОДОВ ШЕРЕМЕТЕВЫХ, КН. ОДОЕВСКИХ И КН. ЧЕРКАССКИХ. ЕЕ ОН ХАРАКТЕРИЗОВАЛ КАК «НЕТИПИЧНЫЙ СЛУЧАЙ», ВО-ПЕРВЫХ, ПО ВЫДАЮЩЕЙСЯ ЗНАТНОСТИ ЭТИХ РОДОВ, А ВО-ВТОРЫХ, ПО СОХРАННОСТИ КОМПЛЕКСА ДОКУМЕНТОВ, КОТОРОМУ НЕТ РАВНЫХ В РУССКИХ ЧАСТНЫХ АКТАХ ${ }^{62}$. ОПРЕДЕЛЕНИЕ ЭТОГО СЛУЧАЯ КАК ТИПИЧНОГО ИЛИ НЕТИПИЧНОГО ПРЕДСТАВЛЯЕТСЯ ВАЖНЫМ ДЛЯ ВЫВОДОВ, КОТОРЫЕ ИЗ НЕГО МОГУТ СЛЕДОВАТЬ, ОДНАКО АРГУМЕНТЫ, ВЫДВИНУТЫЕ КРАММИ В ПОЛЬЗУ НЕТИПИЧНОСТИ, НЕ КАЖУТСЯ МНЕ УБЕДИТЕЛЬНЫМИ. ВО-ПЕРВЫХ, ПОМИМО УКАЗАННЫХ ЗНАТНЫХ РОДОВ, БЫЛИ В ТОЖЕ САМОЕ ВРЕМЯ И ДРУГИЕ, НЕ МЕНЕЕ ЗНАТНЫЕ (НАПРИМЕР, КНЯЗЬЯ ГОЛИЦЫНЫ, ТРУБЕЦКИЕ, ХОВАНСКИЕ, ВОРОТЫНСКИЕ, ПРОЗОРОВСКИЕ, РОМОДАНОВСКИЕ, РЕПНИНЫ, РОМАНОВЫ И ДР.). ВО-ВТОРЫХ УНИКАЛЬНАЯ СОХРАННОСТЬ ДОКУМЕНТОВ САМА ПО СЕБЕ НЕ ПРЕДПОЛАГАЕТ УНИКАЛЬНОСТИ ДАННОЙ «СЕМЕЙНОЙ ИСТОРИИ». СЕМЕЙНУЮ ПАРАДИГМУ ШЕРЕМЕТЕВЫ-ОДОЕВСКИЕ-ЧЕРКАССКИЕ, НА МОЙ ВЗГЛЯД, НЕВОЗМОЖНО ПОКА ОПРЕДЕЛИТЬ В ПОНЯТИЯХ «ТИПИЧНЫЙ - НЕТИПИЧНЫЙ», ИБО МЫ НЕ ИМЕЕМ РЕПРЕЗЕНТАТИВНЫХ ДАННЫХ ДЛЯ ДРУГИХ БОЯРСКИХ СЕМЕЙ XVII В., ОДНАКО ИСКЛЮЧИТЕЛЬНОЙ ЕЕ НАЗВАТЬ НИКАК НЕЛЬЗЯ.

РАССМОТРЕВ ДАННЫЙ «НЕТИПИЧНЫЙ» СЛУЧАЙ, КРАММИ ПРИШЕЛ К СЛЕДУЮЩИМ, В ОСНОВНОМ СПРАВЕДЛИВЫМ, ВЫВОДАМ: 1. ЗЕМЛЮ НАСЛЕДОВАЛИ ПРЯМЫЕ И КОСВЕННЫЕ 
НАСЛЕДНИКИ ${ }^{63}$, И ДАЖЕ ДРУЗЬЯ, Т.Е. ТЕ, КОГО ХОТЕЛ НАЗНАЧИТЬ ЗАВЕЩАТЕЛЬ. (С ЭТИМ НЕВОЗМОЖНО ПОЛНОСТЬЮ СОГЛАСИТЬСЯ, АБСОЛЮТНОЙ СВОБОДЫ ЗАВЕЩАНИЯ НЕ МОГЛО БЫТЬ, НИКАКИЕ «ДРУЗЬЯ» ЗЕМЛЮ НЕ НАСЛЕДОВАЛИ). ЭТИ ВЫДАЮЩИЕСЯ СЕМЬИ СУМЕЛИ УДЕРЖАТЬ И РАСШИРИТЬ СВОИ ВЛАДЕНИЯ В ХVII В.; 2. ЦАРСКАЯ БЛАГОСКЛОННОСТЬ ИГРАЛА БОЛЬШУЮ РОЛЬ В ЭКОНОМИЧЕСКОМ УСПЕХЕ ЭТИХ ФАМИЛИЙ. ИХ СЛУЖБА В ВЫСШИХ ЭШЕЛОНАХ ВЛАСТИ ПОМОГЛА ОБОГАЩЕНИЮ УКАЗАННЫХ СЕМЕЙ. (ЗДЕСЬ СЛЕДУЕТ УТОЧНИТЬ, ЧТО НЕ ТОЛЬКО СЛУЖБА, НО И БЛИЗКАЯ РОДСТВЕННАЯ СВЯЗЬ С ЦАРСКОЙ ФАМИЛИЕЙ СПОСОБСТВОВАЛА ЦАРСКОЙ БЛАГОСКЛОННОСТИ, ЭТО БЫЛ ОДИН ИЗ САМЫХ ВАЖНЫХ ФАКТОРОВ БЛАГОПОЛУЧИЯ УКАЗАННОГО КЛАНА); З. ЭТО ЕЩЕ ОДИН ПРИМЕР ТОГО, ЧТО ХVII В. БЫЛ «ЗОЛОТЫМ ВЕКОМ» БОЯРСТВА, КОГДА ПРАВИТЕЛЬСТВО (СОБСТВЕННО БОЯРЕ И БЫЛИ ПРАВИТЕЛЬСТВОМ - О.К.) СОДЕЙСТВОВАЛО ИХ СЕМЬЯМ ВО ВСЕМ $^{64}$. ЭТОТ ХОРОШО ОБОСНОВАННЫЙ ТЕЗИС КРАММИ БЫЛ НАПРАВЛЕН ПРОТИВ РАННИХ СОВЕТСКИХ ИССЛЕДОВАТЕЛЕЙ (Н.А. РОЖКОВ, М.Н. ПОКРОВСКИЙ, С.В. ВЕСЕЛОВСКИЙ И ДР.), КОТОРЫЕ ВСЛЕД ЗА В.О. КЛЮЧЕВСКИМ ПОВТОРЯЛИ МЫСЛЬ О ТОМ, ЧТО БОЯРСКОЕ ХОЗЯЙСТВО ПОТЕРПЕЛО КРАХ В XVI В. И В XVII В. НАХОДИЛОСЬ В ПОЛНОМ УПАДКЕ. В НАСТОЯЩЕЕ ВРЕМЯ ОНА УЖЕ ВЫШЛА ИЗ НАУЧНОГО УПОТРЕБЛЕНИЯ КАК НЕСОСТОЯТЕЛЬНАЯ.

ПРЕДСТАВЛЯЕТСЯ, ЧТО ВЫВОДЫ Р. КРАММИ ШЕРЕМЕТЕВЫХ-ОДОЕВСКИХ-ЧЕРКАССКИХ ВОЗМОЖНО РАСШИРИТЬ И ДОПОЛНИТЬ. ЗА НЕИМЕНИЕМ БОЛЕЕ ТОЧНОГО ТЕРМИНА, МЫ МОЖЕМ ГОВОРИТЬ О КЛАНЕ, Т.Е. О НЕСКОЛЬКИХ РОДАХ, СВЯЗАННЫХ РОДСТВОМ, СЛУЖБОЙ И ЗЕМЛЕВЛАДЕНИЕМ. ДЛЯ ФЕДОРА ИВАНОВИЧА ШЕРЕМЕТЕВА ВАЖНЕЙШИМИ ОКАЗАЛИСЬ РОДСТВЕННЫЕ СВЯЗИ С НОВОЙ ДИНАСТИЕЙ: И ЧЕРЕЗ ОБЩЕГО ПРЕДКА, И ЧЕРЕЗ ЦАРСКУЮ УГАСНУВШУЮ ДИНАСТИЮ. НО И ДО ВОЦАРЕНИЯ РОМАНОВЫХ СТАРШУЮ ДОЧЬ УЛЬЯНУ ШЕРЕМЕТЕВ УСПЕЛ ВЫДАТЬ ЗА ДАЛЬНЕГО РОДСТВЕННИКА ШУЙСКИХ ГОЛОВИНА, В ТО НЕДОЛГОЕ ВРЕМЯ, КОГДА ВАСИЛИЙ ШУЙСКИЙ ЗАНИМАЛ ЦАРСКИЙ ПРЕСТОЛ. СРЕДИ БРАЧНЫХ ПАРТНЕРОВ ЭТОГО КЛАНА НЕТ ЛЮДЕЙ «НЕРОДОСЛОВНЫХ» ИЛИ «ВЫСКОЧЕК». НАПРОТИВ, ОНИ ПРИНАДЛЕЖАЛИ К ВЫСШЕМУ СЛОЮ ЭЛИТЫ - СЛУЖИЛЫМ КНЯЗЬЯМ ЧЕРКАССКИМ, ТРУБЕЦКИМ, ГОЛИЦЫНЫМ, КУРАКИНЫМ. ОСОБЕННО БЛИЗКИЕ СВЯЗИ СЛОЖИЛИСЬ С КН. ЧЕРКАССКИМИ: БАБУШКА (КН. ИРИНА БОРИСОВНА), ЕЕ ВНУЧКА (КН. ПРАСКОВЬЯ НИКИТИЧНА) И ПРАВНУЧКА (КН. МАРФА ЯКОВЛЕВНА) ВОШЛИ В ЭТОТ РОД, ХОТЯ КН. ЧЕРКАССКИХ НАЗВАТЬ «РОДОМ» МОЖНО ЛИШЬ УСЛОВНО. ВСЕ КНЯЗЬЯ ЧЕРКАССКИЕ КОН. XVI - НАЧ. XVII ВВ. ${ }^{65}$ - ЭТО ЛИЦА, В РАЗНОЕ ВРЕМЯ ВЫЕХАВШИЕ ИЗ КАБАРДЫ И КРЕСТИВШИЕСЯ В МОСКВЕ ПОД ИМЕНЕМ ЧЕРКАССКИХ ${ }^{66}$. НА СВОЕЙ РОДИНЕ ОНИ НЕ СОСТОЯЛИ В РОДСТВЕ, НО В РОССИИ СЧИТАЛИСЬ РОДСТВЕННИКАМИ (ПО ВОЗРАСТУ БРАТЬЯМИ ИЛИ ПЛЕМЯННИКАМИ). НА НОВОЙ РОДИНЕ ОНИ НЕ ИМЕЛИ СТАРОЙ РОДНИ, КОТОРАЯ ОСПАРИВАЛА БЫ НАСЛЕДСТВО ИЛИ МЕСТНИЧАЛА. ЕСТЕСТВЕННО, В МОСКОВСКОМ ГОСУДАРСТВЕ ЧЕРКАССКИЕ НЕ ИМЕЛИ РОДОВЫХ ВОТЧИН, А ТОЛЬКО ВЫСЛУЖЕННЫЕ (Т.Е. ПОЖАЛОВАННЫЕ ЦАРЕМ) ИЗ ДВОРЦОВЫХ ЗЕМЕЛЬ. ЧЕРКАССКИЕ БЫЛИ, ПО ПОНЯТИЯМ ТОГО ВРЕМЕНИ, ПРЕДСТАВИТЕЛЯМИ ИНОЗЕМНОЙ ПРАВЯЩЕЙ ДИНАСТИИ, НАХОДЯЩЕЙСЯ НА СЛУЖБЕ РУССКОГО ЦАРЯ, И ПОРОДНИТЬСЯ С НИМИ БЫЛО ОЧЕНЬ ПОЧЕТНО. КН. ГОЛИЦЫНЫ И КН. ТРУБЕЦКИЕ ЯВЛЯЛИСЬ, КАК И КН. ЧЕРКАССКИЕ, СЛУЖИЛЫМИ КНЯЗЬЯМИ С ИНОЗЕМНЫМИ КОРНЯМИ, ВОСХОДИВШИМИ К РОДУ ГЕДИМИНОВИЧЕЙ. И ЧЕРКАССКИЕ (КН. ПЕТР МИХАЙЛОВИЧ), И ОДОЕВСКИЕ (КН. АННА ЯКОВЛЕВНА) ПОРОДНИЛИСЬ С ГОЛИЦЫНЫМИ В КРАТКИЙ ПЕРИОД ПРАВЛЕНИЯ ЦАРЕВНЫ СОФЬИ (1682-1689 ГГ.), ПРИ КОТОРОЙ РОД ГОЛИЦЫНЫХ СТАЛ ОСОБЕННО 
МОГУЩЕСТВЕННЫМ. НЕ ВЫПАДАЮТ ИЗ ОБЩЕЙ ТЕНДЕНЦИИ И ЕДИНИЧНЫЕ СЛУЧАИ БРАКОВ КН. ОДОЕВСКИХ С КН. КУРАКИНЫМИ, КН. ТРУБЕЦКИМИ, КН. ДОЛГОРУКИМИ, КН. ЛЫКОВО-ОБОЛЕНСКИМИ. ИЗ «НЕРОДОСЛОВНЫХ» ЖЕН В СЕМЬЕ ОДОЕВСКИХ БЫЛА ТОЛЬКО АКУЛИНА ФЕДОРОВНА РТИЩЕВА, ДОЧЬ БЛИЖАЙШЕГО ЦАРСКОГО ФАВОРИТА ОКОЛЬНИЧЕГО ФЕДОРА РТИЩЕВА, КОТОРАЯ ПРЕДСТАВЛЯЛАСЬ ДОСТОЙНОЙ ПАРТИЕЙ.

ПОМИМО ИСКЛЮЧИТЕЛЬНОЙ РОДОВИТОСТИ ЖЕНИХОВ И НЕВЕСТ, ВЫБИРАВШИХСЯ КЛАНОМ ШЕРЕМЕТЕВЫХ-ОДОЕВСКИХ, ИХ ВЫДЕЛЯЛО И БОГАТСТВО, КРУПНЫЕ ЗЕМЕЛЬНЫЕ ВЛАДЕНИЯ. ЗЕМЛИ В ТЕЧЕНИЕ ВЕКА ПЕРЕДАВАЛИСЬ ВНУТРИ ЭТИХ РОДОВ В КАЧЕСТВЕ НАСЛЕДСТВА ИЛИ ПРИДАННОГО, ПОЧТИ НЕ УХОДЯ «НА СТОРОНУ». ДОЧЕРИ В УКАЗАННЫХ СЕМЬЯХ ПОЛУЧАЛИ И БОГАТОЕ ПРИДАННОЕ, И НАСЛЕДСТВО. ЧЕРЕЗ НИХ ОСУЩЕСТВЛЯЛИСЬ РОДСТВЕННЫЕ СВЯЗИ С НАХОДЯЩИМИСЯ В ФАВОРЕ РОДОВИТЫМИ ФАМИЛИЯМИ, ЗЕМЕЛЬНОЕ БОГАТСТВО КОТОРЫХ НАСЛЕДОВАЛИ ПОТОМКИ. НАБЛЮДЕНИЯ, СДЕЛАННЫЕ В. КИВЕЛЬСОН НА ОСНОВЕ ИЗУЧЕНИЯ РОССИЙСКОГО ГОРОДОВОГО ДВОРЯНСТВА XVII В., НЕОЖИДАННО ОКАЗЫВАЮТСЯ ВО МНОГОМ СХОДНЫ И С РАССМАТРИВАЕМОЙ «БОЯРСКОЙ» СИТУАЦИЕЙ. «КРУГОВОРОТ» СЕМЕЙНОЙ ЗЕМЛИ, КОТОРАЯ УХОДИЛА ПО ЖЕНСКОЙ ЛИНИИ В ДРУГОЙ РОД, А СО ВРЕМЕНЕМ ВОЗВРАЩАЛАСЬ В НЕГО ЖЕ ЧЕРЕЗ НАСЛЕДСТВО И ДРУГИЕ БРАКИ, ЯСНО ПРОСЛЕЖИВАЕТСЯ И В НАШЕМ «БОЯРСКОМ» СЛУЧАЕ: КАК ПИШЕТ КИВЕЛЬСОН, «What goes around, comes around [ЧТО ИДЕТ ПО КРУГУ, ТО - ВОЗВРАЩАЕТСЯ]» ${ }^{67}$.

РОДОНАЧАЛЬНИКОМ КЛАНА Ф.И. ШЕРЕМЕТЕВЫМ БЫЛА ЗАЛОЖЕНА ПРАКТИКА ПЕРЕДАЧИ ОСНОВНОЙ НАСЛЕДСТВЕННОЙ МАССЫ ОДНОМУ ИЗ НАСЛЕДНИКОВ, А НЕ РАВНЫЙ РАЗДЕЛ. ПРИЧЕМ ЕМУ ЖЕ (САМОМУ МЛАДШЕМУ) ПО ВОЛЕ Ф.И. ШЕРЕМЕТЕВА ЗАВЕЩАЛИ ОСОБО КРУПНЫЕ ВЛАДЕНИЯ ЕГО МАТЬ И ОТЕЦ. НО НАСЛЕДОВАНИЕ РАСПРЕДЕЛЯЛОСЬ ТАКИМ ОБРАЗОМ, ЧТО И ДРУГИЕ ЧЛЕНЫ СЕМЬИ ТОЖЕ ПОЛУЧАЛИ СОЛИДНУЮ ЧАСТЬ ${ }^{68}$.

КОНЕЧНО, В ИСТОРИЮ СЕМЕЙ ВМЕШИВАЛИСЬ ПОЛИТИЧЕСКИЕ СОБЫТИЯ, А ТАКЖЕ БОЛЕЗНИ И СМЕРТИ, ПРОИСХОДИВШИЕ НЕ ВСЕГДА В СТАРОСТИ, МЕНЯЛОСЬ ВРЕМЯ МЕНЯЛИСЬ НРАВЫ И ОБСТОЯТЕЛЬСТВА. ТЕМ НЕ МЕНЕЕ, НА МОЙ ВЗГЛЯД, ПЕРЕПЛЕТЕНИЕ БРАЧНЫХ УЗ И ЗЕМЕЛЬНЫХ ВЛАДЕНИЙ, О КОТОРЫХ Я ТАК ДОЛГО ПОВЕСТВОВАЛА, ПОМОГАЕТ УВИДЕТЬ НАМ ТО, ЧТО Я ПОЛАГАЮ ВОЗМОЖНЫМ УСЛОВНО ОПРЕДЕЛИТЬ ИМЕННО КАК КЛАН, КАК СВОЕОБРАЗНЫЙ АЛЬЯНС. КЛАН, ОСНОВУ КОТОРОГО СОСТАВЛЯЛИ ШЕРЕМЕТЕВЫ, КН. ОДОЕВСКИЕ, КН. ЧЕРКАССКИЕ И НЕКОТОРЫЕ ДРУГИЕ ФАМИЛИИ, ВХОДИВШИЕ С НИМИ В ПЕРМАНЕНТНУЮ СВЯЗЬ. КЛАН НЕ РАВЕН РОДУ ИЛИ ФАМИЛИИ: КАК МЫ ВИДЕЛИ, БРАТЬЯ ШЕРЕМЕТЕВЫ ОКАЗАЛИСЬ ВО ВРАЖДЕБНЫХ ОТНОШЕНИЯХ ДРУГ К ДРУГУ В НАЧАЛЕ ВЕКА, И ШЕРЕМЕТЕВЫ - «ПЕТРОВИЧИ» ПРЕДСТАВЛЯЛИ СОБОЙ ДРУГОЙ КЛАН, ХОТЯ И ЯВЛЯЛИСЬ ОДНИМ РОДОМ.

\section{Род Шереметевых: ветвь Петра Никитича Шереметева (браки и землевладение)}

«ПЕТРОВИЧИ» (ИВАН, ВАСИЛИЙ И БОРИС) БЫЛИ ГОРАЗДО БЕДНЕЕ ФЕДОРА ИВАНОВИЧА ШЕРЕМЕТЕВА, ИМЕВШЕГО ПО ОКОНЧАНИИ СМУТНОГО ВРЕМЕНИ (В 20-ЕГГ.) 1516 КРЕСТЬЯНСКИХ ДВОРОВ В РАЗНЫХ УЕЗДАХ ${ }^{69}$. ОНИ РАЗДЕЛИЛИ НАСЛЕДСТВО СВОЕГО ОТЦА ПЕТРА НИКИТИЧА - 1173 ЧЕТВЕРТИ ЗЕМЛИ, ИЗ ПРИНАДЛЕЖАВШИХ ЕМУ 3519 ЧЕТВЕРТЕЙ. СТАРТОВЫЕ ПОЗИЦИИ МОЛОДЫХ «ПЕТРОВИЧЕЙ», ЕЩЕ ПРЕБЫВАВШИХ В ЧИНЕ МОСКОВСКИХ ДВОРЯН, В ЭТОТ ПЕРИОД ТАКОВЫ: 

ПЕТРОВИЧЕМ - 738 ДВОРОВ, ЗА БОРИСОМ ПЕТРОВИЧЕМ - 202 ДВОРА ${ }^{73}$. ВСЕ «ПЕТРОВИЧИ» ПРОИЗВЕЛИ НА СВЕТ МНОГОЧИСЛЕННОЕ ПОТОМСТВО. ТОЛЬКО БОЯРИН БОРИС ПЕТРОВИЧ МЕНЬШОЙ ИМЕЛ ЕДИНСТВЕННОГО СЫНА ВАСИЛИЯ И ЕДИНСТВЕННОГО ВНУКА ИВАНА. К СОЖАЛЕНИЮ, СВЕДЕНИЯ О ЗЕМЛЕВЛАДЕНИИ ШЕРЕМЕТЕВЫХ ВО ВТОРОЙ ПОЛОВИНЕ ХVII В. ОТРЫВОЧНЫ $^{74}$, А ЗАВЕЩАНИЯ, ПО КОТОРЫМ МОЖНО СУДИТЬ О ПОЛИТИКЕ РАСПРЕДЕЛЕНИЯ НАСЛЕДСТВЕННЫХ ЗЕМЕЛЬ, МАЛОЧИСЛЕННЫ (ИХ ТОЛЬКО ДВА: ИВАНА ПЕТРОВИЧА ШЕРЕМЕТЕВА, КОТОРЫЙ ЗА НЕДЕЛЮ ДО СМЕРТИ В 1647 Г. РАЗДЕЛИЛ ВСЮ НЕДВИЖИМОСТЬ В РАВНЫХ ДОЛЯХ МЕЖДУ ЖЕНОЙ И ДЕТЬМИ ${ }^{75}$, И ВАСИЛИЯ БОРИСОВИЧА ШЕРЕМЕТЕВА, ЗАВЕЩАВШЕГО БОЛЬШУЮ ЧАСТЬ НЕДВИЖИМОСТИ ЗАМУЖНЕЙ ДОЧЕРИ ЕВФИМЬЕ ГОЛИЦЫНОЙ, БРАТУ И ПЛЕМЯННИКАМ $)^{76}$ И - НИЧЕГО - СВОЕМУ СЫНУ, КОТОРОМУ, ВИДИМО, БЫЛИ ВЫДЕЛЕНЫ ЗЕМЛИ ЕЩЕ ПРИ ЖИЗНИ ОТЦА. ЗАТО В ПЕТРОВСКОЕ ВРЕМЯ, КОГДА ВВЕЛИ ПРАВИЛО ЗАПИСИ ВСЕХ ЮРИДИЧЕСКИХ ДОКУМЕНТОВ В КРЕПОСТНЫХ КОНТОРАХ, ТАКИХ ДОКУМЕНТОВ СОХРАНИЛОСЬ НЕМАЛО (5 ДУХОВНЫХ, 3 СГОВОРНЫХ И 3 РЯДНЫХ), И ОНИ БЫЛИ НЕДАВНО ВЫЯВЛЕНЫ И ОПУБЛИКОВАНЫ ${ }^{77}$.

47 ПРЕДСТАВИТЕЛИ ЭТОЙ ВЕТВИ РОДА ШЕРЕМЕТЕВЫХ МНОГО МЕСТНИЧАЛИ, В ТОМ ЧИСЛЕ ИВАН ПЕТРОВИЧ ШЕРЕМЕТЕВ МЕСТНИЧАЛ В 1645 Г. С КН. НИКИТОЙ ИВАНОВИЧЕМ ОДОЕВСКИМ, НО СПОР ПРОИГРАЛ ${ }^{78}$. ДЕТИ И ВНУКИ «ПЕТРОВИЧЕЙ», КАК ОТМЕЧАЛ С.М. СОЛОВЬЕВ, «ЛИЧНЫМ ДОСТОИНСТВОМ ПОДДЕРЖИВАЛИ ЗНАЧЕНИЕ СВОЕЙ ФАМИЛИИ» 79. ДВОЮРОДНЫЕ БРАТЬЯ ПЕТР ВАСИЛЬЕВИЧ И ВАСИЛИЙ БОРИСОВИЧ, КАК И ИХ ОТЦЫ, ОТДАВАЛИ ДАНЬ ВОЕННОЙ И АДМИНИСТРАТИВНОЙ ДЕЯТЕЛЬНОСТИ, ОКАЗАВШЕЙСЯ ТЕСНО СВЯЗАННОЙ С ПРОЦЕССОМ ПРИСОЕДИНЕНИЯ УКРАИНЫ К РОССИИ. ЗА СВОЮ СЛУЖБУ ОНИ ИМЕЛИ КАК ЦАРСКИЕ ВЫСОКИЕ ПОЖАЛОВАНИЯ, ТАК И СУРОВЫЕ ВЫГОВОРЫ И НАРЕКАНИЯ. ШЕРЕМЕТЕВЫ ВСЕГДА ПРИСУТСТВОВАЛИ НА ВАЖНЫХ ДВОРЦОВЫХ ЦЕРЕМОНИЯХ. СОХРАНИЛОСЬ НЕСКОЛЬКО ПИСЕМ ЦАРЯ АЛЕКСЕЯ МИХАЙЛОВИЧА К ШЕРЕМЕТЕВЫМ, В КОТОРЫХ ВИДНО ЕГО УВАЖИТЕЛЬНОЕ ОТНОШЕНИЕ К ЭТОМУ РОДУ В ЦЕЛОМ. ОДНАКО, ОСТАВЛЯЯ ВОПРОС О СЛУЖЕБНОЙ ИСТОРИИ ШЕРЕМЕТЕВЫХ, КОТОРАЯ ХОРОШО ОСВЕЩЕНА ВО МНОГИХ ИЗДАНИЯХ, ПОСМОТРИМ НА ИХ БРАЧНУЮ СТРАТЕГИЮ.

ПЕТР НИКИТИЧ ШЕРЕМЕТЕВ (УМ. 1609) СДЕЛАЛ ДЛЯ СВОЕГО ВРЕМЕНИ ОЧЕНЬ ДОСТОЙНУЮ ПАРТИЮ - ЕГО ПЕРВОЙ ЖЕНОЙ БЫЛА ДОЧЬ ИВАНА ФЕДОРОВИЧА НАГОГО (УМ. 1597 Г.), ВИДИМО, СЕСТРА ЖЕНЫ ИВАНА ГРОЗНОГО ЦАРИЦЫ МАРЬИ НАГОЙ. ОДНАКО ВРЕМЕНА ИЗМЕНИЛИСЬ, И НАГИЕ, СКОМПРОМЕТИРОВАВШИЕ СЕБЯ ИСТОРИЕЙ СО СМЕРТЬЮ И «ВОСКРЕСЕНИЕМ» СЫНА МАРЬИ ЦАРЕВИЧА ДИМИТРИЯ, ОКАЗАЛИСЬ ВДАЛИ ОТ ДОМА РОМАНОВЫХ. ВТОРОЙ ЖЕНОЙ ПЕТРА НИКИТИЧА БЫЛА КНЯЖНА ФЕОДОСЬЯ БОРИСОВНА ДОЛГОРУКАЯ ${ }^{80}$. 

ВЫХОДИЛИ ЗАМУЖ СЛЕДУЮЩИМ ОБРАЗОМ: АННА ИВАНОВНА - ЗА ИВАНОМ ИВАНОВИЧЕМ
САЛТЫКОВЫМ; МАРФА ВАСИЛЬЕВНА - ЗА ЛЬВОМ АЛЕКСАНДРОВИЧЕМ ШЛЯКОВ-ЧЕШСКИМ;
ЕВФИМИЯ ВАСИЛЬЕВНА - ЗА ЯКОВОМ АЛЕКСЕЕВИЧЕМ ГОЛИЦЫНЫМ (УМ. 1683 Г.); АННА ВАСИЛЬЕВНА - ЗА КН. ВАСИЛИЕМ ПЕТРОВИЧЕМ ЩЕРБАТОВЫМ.

ДАЖЕ ТАКОЙ ПРОСТОЙ ПЕРЕЧНЕВЫЙ ПОДХОД К СУПРУЖЕСКИМ ПАРАМ ПОКАЗЫВАЕТ РАЗНИЦУ БРАЧНЫХ И НАСЛЕДСТВЕННЫХ СТРАТЕГИЙ В ВЕТВИ «ШЕРЕМЕТЕВЫ-ОДОЕВСКИЕ» И ВЕТВИ ШЕРЕМЕТЕВЫ-«ПЕТРОВИЧИ॥. В ОТЛИЧИЕ ОТ ВЕТВИ РОДА ФЕДОРА ИВАНОВИЧА ШЕРЕМЕТЕВА, «ПЕТРОВИЧИ» ИМЕЛИ МАЛОЕ КОЛИЧЕСТВО ЖЕН ИЗ ПРЕДСТАВИТЕЛЬНИЦ КНЯЖЕСКИХ РОДОВ (КН. ПРОНСКАЯ, КН. ПОЖАРСКАЯ, КН. ЛЬВОВА, КН. КУРАКИНА, КН. ЧЕРКАССКАЯ). НО И ОНИ (ЗА ИСКЛЮЧЕНИЕМ ДВУХ ПОСЛЕДНИХ), НЕ ОТНОСИЛИСЬ К ПЕРВОСТАТЕЙНЫМ РОДАМ ПРИ РОМАНОВЫХ. БРАК МАРФЫ ВАСИЛЬЕВНЫ ШЕРЕМЕТЕВОЙ СО ЗНАТНЫМ ИНОЗЕМЦЕМ ЛЬВОМ ШЛЯКОВЫМ-ЧЕШСКИМ ЗАКОНЧИЛСЯ КОНФУЗОМ, ЖЕНИХ ОКАЗАЛСЯ САМОЗВАНЦЕМ. СРЕДИ ЖЕН «ПЕТРОВИЧЕЙ» ВЫДЕЛЯЮТСЯ ДОЧЕРИ НЕРОДОВИТЫХ, НО ВЫСОКОПОСТАВЛЕННЫХ ОТЦОВ: ДОЧЬ БОГАТОГО И ВЛИЯТЕЛЬНОГО ДЬЯКА РАЗРЯДНОГО ПРИКАЗА И. ГАВРЕНЕВА, ДОЧЬ ЦАРСКОГО ЛЮБИМЦА И РОДСТВЕННИКА ПО ЖЕНЕ СОКОЛЬНИЧЕГО АФАНАСИЯ МАТЮШКИНА, ЕВФИМЬЯ МИЛОСЛАВСКАЯ (НЕИЗВЕСТНО КЕМ ПРИХОДЯЩАЯСЯ ЦАРИЦЕ МАРЬЕ МИЛОСЛАВСКОЙ), ВДОВА ДЯДИ ПЕТРА І ЛЬВА НАРЫШКИНА АННА НАРЫШКИНА. ТАКИЕ ЖЕНЫ «ПЕТРОВИЧЕЙ» КАК ВЫЛУЗГИНА, КОРОБЬИНА, ПОЛЕВАЯ, ТРЕТЬЯКОВА, ЧИРИКОВА, ПУШКИНА, СВИНЬИНА - ПРЕДСТАВИТЕЛЬНИЦЫ СТАРЫХ, НО ПРОСТЫХ, «НЕДУМНЫХ», ДВОРЯНСКИХ РОДОВ, НАВЕРНЯКА НЕ ВЛАДЕВШИХ БОЛЬШИМИ ЗЕМЛЯМИ. НО ПОДОБНЫЕ БРАКИ БЫЛИ ОБЫЧНЫМИ И НЕ ПОЗОРИЛИ РОДОВИТЫЕ СЕМЬИ. ИНАЧЕ ГОВОРЯ, В ЭТОЙ ГРУППЕ ЗНАТИ ДЕЙСТВОВАЛИ ИНЫЕ БРАЧНЫЕ ПРАКТИКИ, ВОЗМОЖНО, БЫЛИ ИНЫЕ ВЗГЛЯДЫ. 


\section{О брачных стратегиях российской знати}

ЗНАТИ, ПОКА УДАЕТСЯ С БОЛЬШИМ ТРУДОМ ИЗ-ЗА НЕПОЛНОТЫ СВЕДЕНИЙ О ЖЕНАХ, ОДНАКО ИСТОРИКИ НЕ ОБХОДЯТ ЕЕ СВОИМ ВНИМАНИЕМ. ТАК, РОБЕРТ КРАММИ, РАССМАТРИВАЯ ПУТИ ВХОЖДЕНИЯ ВЕРХНЕОКСКИХ УДЕЛЬНЫХ КНЯЗЕЙ МОСКОВСКОГО ГОСУДАРЕВА ДВОРА, ПИСАЛ, ЧТО К ХVII ВЕКУ «РОДЫ, ЗАНИМАВШИЕ ВЕРШИНЫ СОЦИАЛЬНОЙ И АДМИНИСТРАТИВНОЙ СТРУКТУРЫ, СОЗДАЛИ ТЩАТЕЛЬНО РАЗРАБОТАННУЮ МАТРИМОНИАЛЬНУЮ СЕТЬ (КУРСИВ МОЙ - О.К.), СВЯЗАВШУЮ ИХ С ПРАВЯЩЕЙ ДИНАСТИЕЙ, ЕЕ БЛИЖАЙШИМИ РОДСТВЕННИКАМИ, А ТАКЖЕ КАК МОЖНО БОЛЬШИМ ЧИСЛОМ ДРУГИХ ФАМИЛИЙ» ${ }^{83}$. ЗАТО ДРУГ С ДРУГОМ ВЕРХНЕОКСКИЕ КНЯЗЬЯ БРАЧНЫХ СВЯЗЕЙ НЕ СОЗДАВАЛИ И КАКОГО-ЛИБО «ВЕРХНЕОКСКОГО КЛАНА» СОБОЙ НЕ ПРЕДСТАВЛЯЛИ. ПРАКТИЧЕСКИ К ТАКИМ ЖЕ ВЫВОДАМ ПРИШЕЛ И В.Д. НАЗАРОВ, ИЗУЧАЯ ВХОЖДЕНИЕ В МОСКОВСКИЙ ДВОР КН. РОМОДАНОВСКИХ:

БРАКИ РОМОДАНОВСКИХ [...] НЕ ЗАХВАТЫВАЛИ ВЫСШИЕ СЛОИ АРИСТОКРАТИИ, А ОГРАНИЧИВАЛИСЬ МЕНЕЕ ЗНАЧИМЫМИ КРУГАМИ ЗНАТИ. ПЕРЕВЕС НЕТИТУЛОВАННЫХ ФАМИЛИЙ ОБЪЯСНИМ: АКТИВНОЕ ВРАСТАНИЕ РОМОДАНОВСКИХ В ВЕЛИКОКНЯЖЕСКИЙ ДВОР С КОНЦА XV В. РАСШИРЯЛО ИХ КОНТАКТЫ В ПЕРВУЮ ОЧЕРЕДЬ С БОЯРСКИМИ РОДАМИ, ДАВНО СЛУЖИВШИМ МОСКОВСКИМ ГОСУДАРЯМ. ${ }^{84}$

ВЕРОЯТНО, БОЛЬШАЯ ВАРИАТИВНОСТЬ БРАЧНЫХ СВЯЗЕЙ ЗНАТИ НАЧАЛАСЬ С ФОРМИРОВАНИЕМ МОСКОВСКОГО ГОСУДАРСТВА И ТРАДИЦИОННО СОХРАНИЛАСЬ ДО БОЛЕЕ ПОЗДНИХ ВРЕМЕН. С.В. ЛОБАЧЕВ, ОБРАЩАЯСЬ К БОЯРСКИМ ДУХОВНЫМ ГРАМОТАМ ХVII В., НЕ НАШЕЛ ЛОГИКИ В БРАЧНЫХ СВЯЗЯХ БОЯРСТВА:

В СЕТИ РОДСТВЕННЫХ СВЯЗЕЙ БОЯРСКОЙ АРИСТОКРАТИИ ДОВОЛЬНО ТРУДНО НАЙТИ КАКУЮ-НИБУДЬ ЗАКОНОМЕРНОСТЬ (КУРСИВ МОЙ - О.К.). ИМЕНИТЫЕ КНЯЖЕСКИЕ ФАМИЛИИ ОКАЗЫВАЮТСЯ В РОДСТВЕ КАК С ПРАВЯЩЕЙ ДИНАСТИЕЙ, ТАК И С НЕРОДОВИТЫМИ СЕМЬЯМИ, НАПРИМЕР, С СЕМЬЯМИ ДЬЯКОВ. ПУБЛИКУЕМЫЕ НИЖЕ ИСТОЧНИКИ НЕ МОГУТ РАСПУТАТЬ ЭТИ СЕТИ. ${ }^{85}$

ВАЛЕРИЯ КИВЕЛЬСОН ПЫТАЛАСЬ ПРОСЛЕДИТЬ ОПРЕДЕЛЕННУЮ СИСТЕМУ В ЗАКЛЮЧЕНИИ БРАКОВ В СРЕДЕ ГОРОДОВОГО ДВОРЯНСТВА. ОНА ПРИШЛА К ВЫВОДУ О ТОМ, ЧТО И ЗДЕСЬ РЕДКО СКРЕПЛЯЛИСЬ СОЮЗЫ МЕЖДУ ВЕТВЯМИ ОДНОГО РОДА И ЗЕМЛЮ НЕ СТРЕМИЛИСЬ ОБЯЗАТЕЛЬНО ПЕРЕДАВАТЬ ПО МУЖСКОЙ ЛИНИИ. ВЫБОР ЖЕНИХА ИЛИ НЕВЕСТЫ ОПРЕДЕЛЯЛА СУЩЕСТВОВАВШАЯ В СЕМЬЕ НА ДАННЫЙ МОМЕНТ СИТУАЦИЯ. ПАРЫ ОБЫЧНО СОСТАВЛЯЛИСЬ ИЗ ДВОРЯНСКИХ ПРЕДСТАВИТЕЛЕЙ СВОЕГО «ГОРОДА» И ОСНОВЫВАЛИСЬ В ПЕРВУЮ ОЧЕРЕДЬ НА ЭКОНОМИЧЕСКОМ ДОХОДЕ, ПОЛУЧАЕМОМ КОНКРЕТНОЙ СЕМЬЕЙ. БРАКИ НЕ ОРИЕНТИРОВАЛИ НА «ВЫСОКУЮ ПОЛИТИКУ» ВХОЖДЕНИЯ СЕМЬИ В КАКОЙ-ЛИБО МОСКОВСКИЙ КЛАН ${ }^{86}$. ВАЛЕРИЯ КИВЕЛЬСОН РАЗГРАНИЧИВАЛА БЫТИЕ ДВОРЯНСТВА ПРОВИНЦИИ, ЗАНЯТОГО СВОИМИ МЕСТНЫМИ ИНТЕРЕСАМИ, И ЖИЗНЬ МОСКОВСКОЙ ЗНАТИ, ПОГРУЖЕННОЙ В ПОЛИТИЧЕСКУЮ БОРЬБУ ПРИ ДВОРЕ. ОДНАКО, НА МОЙ ВЗГЛЯД, В НИХ БЫЛО МНОГО ОБЩЕГО - МОСКОВСКИЕ ЗНАТНЫЕ СЕМЬИ, КАК И СЕМЬИ ДРУГИХ ГОРОДОВ, ОРИЕНТИРОВАЛИСЬ НА СВОИ СИТУАТИВНЫЕ ИНТЕРЕСЫ И ПРОБЛЕМЫ. ТОЛЬКО В ЭТИ ПРОБЛЕМЫ ВПЛЕТАЛИСЬ И ПОСТОЯННЫЕ ПЕРЕМЕНЫ ПРИ ДВОРЕ, ПОЯВЛЕНИЕ ФАВОРИТОВ, ОПРЕДЕЛЕННЫЕ СЛУЖЕБНЫЕ НАЗНАЧЕНИЯ, ОПАЛЫ И ПРОЧ. ИТАК, В ЦЕЛОМ НЕ УДАЕТСЯ ПРОСЛЕДИТЬ ОПРЕДЕЛЕННУЮ ЛОГИКУ В ЗАКЛЮЧЕНИИ БРАКОВ СРЕДИ ЗНАТИ XVII В. ОДНАКО ПРОДЕЛАННОЕ ИССЛЕДОВАНИЕ ПОКАЗЫВАЕТ, ЧТО 
ОНА МОГЛА РАЗЛИЧАТЬСЯ В РАЗНЫХ КЛАНАХ. ВИДИМО В РАССМАТРИВАЕМОЙ СРЕДЕ ДОЛЖНО БЫЛО СУЩЕСТВОВАТЬ ПОНЯТИЕ РАВНЫХ И НЕРАВНЫХ БРАКОВ, НО ЕГО КРИТЕРИЕВ ПОКА УТОЧНИТЬ НЕ УДАЕТСЯ. ЯСЕН ТОЛЬКО ОДИН ПРИОРИТЕТ ПРИ ЗАКЛЮЧЕНИИ БРАКА - СТАТЬ БЛИЖЕ К ЦАРСКОЙ СЕМЬЕ И ЕЕ ФАВОРИТАМ. ПРЕДСТАВЛЯЕТСЯ, ЧТО ПРИ СГОВОРЕ МОГЛО ИГРАТЬ СУЩЕСТВЕННУЮ РОЛЬ ПРИДАНОЕ НЕВЕСТЫ, НО ЧТО БЫЛО ВАЖНЕЕ ДЛЯ ЖЕНИХА - СТАТУС ИЛИ БОГАТСТВО - ЭТОТ ВОПРОС ОСТАЕТСЯ ОТКРЫТЫМ.

БЕЗ ОТВЕТА ОСТАЕТСЯ И ВОПРОС О РОЛИ ЗЕМЕЛЬНЫХ ВЛАДЕНИЙ ПРИ ЗАКЛЮЧЕНИИ БРАКОВ. В СВОЕ ВРЕМЯ С.В. РОЖДЕСТВЕНСКИЙ, ОСНОВЫВАЯСЬ НА ДАННЫХ РАСПИСНОГО СПИСКА ЗЕМЕЛЬ ДУМНЫХ ЛЮДЕЙ 1647 Г. ПОКАЗАЛ РАЗБРОСАННОСТЬ БОЯРСКИХ ВОТЧИН ПО РАЗНЫМ УЕЗДАМ. ЭТО ПРИВЕЛО ЕГО К ВЫВОДУ О ТОМ, ЧТО НИ ОДИН «СЛОЙ МОСКОВСКОГО СЛУЖИЛОГО ОБЩЕСТВА» НЕ СМОГ ОБРАЗОВАТЬ ЗАМКНУТОЙ ЗЕМЛЕВЛАДЕЛЬЧЕСКОЙ АРИСТОКРАТИИ» ${ }^{87}$. ОДНАКО КОЛИЧЕСТВЕННЫЙ АНАЛИЗ БОЯРСКИХ КРЕПОСТНЫХ ДВОРОВ ПО ЗЕМЕЛЬНЫМ РОСПИСЯМ 1647 И 1678 ГГ. ПОКАЗЫВАЕТ, ЧТО В ОДНИХ УЕЗДАХ ИХ ВЛАДЕНИЯ СОСТАВЛЯЛИ ЛИШЬ НЕСКОЛЬКО ДВОРОВ, ЗАТО В ДРУГИХ - ЗАНИМАЛИ КОЛОССАЛЬНЫЕ ТЕРРИТОРИИ ${ }^{88}$. ВОЗМОЖНО ПРЕДПОЛОЖИТЬ, ЧТО КЛАНЫ ВОЗНИКАЛИ НА ОСНОВЕ ЖЕЛАНИЯ СОЗДАВАТЬ И УДЕРЖИВАТЬ ПОДОБНЫЕ КРУПНЫЕ ЗЕМЕЛЬНЫЕ ВЛАДЕНИЯ, СВЯЗЫВАЯ ЭТО НЕ С ПОЛИТИКОЙ, А С ЭКОНОМИКОЙ. ЭТО ПРЕДПОЛОЖЕНИЕ ТРЕБУЕТ ДАЛЬНЕЙШИХ СПЕЦИАЛЬНЫХ ИССЛЕДОВАНИЙ, В КОТОРЫХ ДОЛЖНЫ БЫТЬ РАССМОТРЕНЫ БРАКИ И НАСЛЕДОВАНИЕ В ИХ СВЯЗИ С ЗЕМЕЛЬНЫМИ ИМЕНИЯМИ.

\section{NOTES}

2. Г.Г. ЛУКЬЯНОВ, РЕД., ЧАСТНАЯ ПЕРЕПИСКА КНЯЗЯ ПЕТРА ИВАНОВИЧА ХОВАНСКОГО, ЕГО СЕМЬИ И РОДСТВЕННИКОВ, М., 1905, С. 21, 28, 29, 34, 35.

3. С.И. КОТКОВ, РЕД., МОСКОВСКАЯ ДЕЛОВАЯ И БЫТОВАЯ ПИСЬМЕННОСТЬ ХVII ВЕКА, М., 1968, С. 18.

4. ЗАПИСКИ ОБЩЕСТВА РУССКОЙ И СЛАВЯНСКОЙ АРХЕОЛОГИИ ИМПЕРАТОРСКОГО АРХЕОЛОГИЧЕСКОГО ОБЩЕСТВА, СПБ., 1861, Т. 2, С. $736-737$.

5. ОЛЬГА В. НОВОХАТКО, «ПРЕДУВЕДОМЛЕНИЕ» В: ОЛЬГА В. НОВОХАТКО, РЕД., АРХИВ СТОЛЬНИКА АНДРЕЯ ИЛЬИЧА БЕЗОБРАЗОВА, Ч. 1, М., 2012, С. 3-4.

6. Nancy Shields Kollman, «The Boyar Clan and Court Politics: the Founding of the Muscovite Political System», Cahiers du monde russe et soviétique, 23 (1), 1982, p. 5-31; N. Sh. Kollman, Kinship and Politics: The Making of the Muscovite Political System, 1345-1547, Stanford University press, 1987.

7. Robert O. Crummey, Aristocrats and Servitors: The Boyar Elite of Russia, 1613-1689, Princeton, 1983; Ed. Keenan, «Muscovite Political Folkways», Russian Review, 45, 1986, c. 133-136.

8. Valerie Kivelson, Autocracy in the Provinces: The Muscovite Gentry and Political Culture in the Century, Stanford University press, 1996, c. 102.

9. Kivelson, Autocracy in the Provinces, c. 103.

10. Marshall Poe, The Russian Elite in the Seventeenth Century, vol. 2.: A Quantitative Analysis of The “Duma Ranks," (1613-1713), c. 26.

11. ПАВЕЛ В. СЕДОВ, ЗАКАТ МОСКОВСКОГО ЦАРСТВА, СПБ., 2006, С. 92. 
12. МАРШАЛ ПО ПИШЕТ ОБ ЭТОМ ЖЕ, НО ВНЕ КОНТЕКСТА СЕМЬИ: «We will take it for granted that one of the primary ends of the political game...was the maintenance and acquisition of power, honor, and wealth» (Poe, The Russian Elite in the Seventeenth Century, vol. 2, c. 27).

13. ТАТЬЯНА А. ОПАРИНА, ИНОЗЕМЦЫ В РОССИИ В XVI-XVII ВВ., М., 2007.

14. L.A. Farrow, «Peter the Great's Law of Single Inheritance: State Imperatives and Noble Resistance», Russian Review, 55 (3), 1996, c. 430-447.

15. УКАЗ ОТ 1 МАРТА 1731 Г., ОТМЕНЯЮЩИЙ ПЕТРОВСКИЙ УКАЗ «О ЕДИНОНАСЛЕДИИ». ПОЛНОЕ СОБРАНИЕ ЗАКОНОВ РОССИЙСКОЙ ИМПЕРИИ, Т. ХVIII, СПБ., 1830, № 5717 (Д???? ???).АЛЕЕ ПСЗ).

16. ПСЗ, Т. ХVIII, № 5657; О???? ?.????????,ЛЬГА Е. КОШЕЛЕВА, «ДЕТИ КАК НАСЛЕДНИКИ В РУССКОМ ПРАВЕ С ДРЕВНЕЙШИХ ВРЕМЕН ДО ПЕТРОВСКОГО ВРЕМЕНИ», СОЦИАЛЬНАЯ ИСТОРИЯ. ЕЖЕГОДНИК 1998/99, С. 200-202.

17. Daniel H. Kaiser, «Women, Property and the Law ...», unpublished; Kivelson, Autocracy in the Provinces; Crummey, Aristocrats and Servitors, p. 115; НАДА БОШКОВСКА, МИР РУсСКОЙ ЖЕНЩИНЫ В ХVII СТОЛЕТИИ, СПБ., 2014, с. 308-310; МИШЕЛЬ ЛАМАРШ МАРРЕЗЕ, БАБЬЕ ЦАРСТВО: ДВОРЯНКИ И ВЛАДЕНИЕ ИМУЩЕСТВОМ В РОССИИ (1700-1861), М., 2009.

18. О ТРАДИцИЯХ ПОмИНовЕНИЯ см.: Ludwig Steindorff, Memoria in Altrußland: Untersuchungen zu den Formen christlicher Totensorge, Stuttgart, 1994.

19. ИЗВЕСТИЯ РУССКОГО ГЕНЕАЛОГИЧЕСКОГО ОБЩЕСТВА, 1911, № 4, с. 379-391.

20. ПОТОМКИ ВЫПОЛНЯЛИ ЕГО ЗАВЕТ: ИЗВЕСТНО, ЧТО ВНУК Н.И.ОДОЕВСКОГО ЮРИЙ МИХАЙЛОВИЧ ДАЛ В ДОМОВУЮ ЦЕРКОВЬ ЗНАМЕНИЯ БОГОРОДИЦЫ ВКЛАД - ДОРОГОЙ ИЛЛЮМИНИРОВАННЫЙ СБОРНИК, СДЕЛАННЫЙ В НОВГОРОДЕ В ЕГО БЫТНОСТЬ ТАМ ВОЕВОДОЙ, ВИДИМО, СПЕЦИАЛЬНО ПО ЕГО ЗАКАЗУ. (В.И. МАЛЫШЕВ, «О ВКЛАДНОЙ ЗАПИСИ НА ЛИЦЕВОМ СБОРНИКЕ XVII В. ИЗ КОЛЛЕКЦИИ Ф.А. КАЛИКИНА», ТРУДЫ ОТДЕЛА ДРЕВНЕРУССКОЙ ЛИТЕРАТУРЫ, 1972, № 27, с. 454-456).

21. СЕРГЕЙ В. ЛОБАЧЕВ, «ИЗУЧЕНИЕ ГЕНЕАЛОГИИ БОЯРСКОЙ АРИСТОКРАТИИ ХVII ВЕКА НА МАТЕРИАЛАХ ДУХОВНЫХ ЗАВЕЩАНИЙ», РУССКОЕ ПРОШЛОЕ. ИСТОРИКО-ДОКУМЕНТАЛЬНЫЙ АЛЬМАНАХ , КН. 8, СПБ., 1998, С. 332.

22. ЛУКЬЯНОВ, РЕД., ЧАСТНАЯ ПЕРЕПИСКА КНЯЗЯ ПЕТРА ИВАНОВИЧА ХОВАНСКОГО, ЕГО СЕМЬИ И РОДСТВЕННИКОВ, С. 29.

23. НЕЛЬЗЯ НЕ ОТМЕТИТЬ И ТЕНДЕНЦИЮ НЕ ДОВЕРЯТЬ СВОЕ ПОМИНОВЕНИЕ ПОТОМСТВУ И ОРГАНИЗОВЫВАТЬ САМОСТОЯТЕЛЬНО СВОЕ ПОМИНОВЕНИЕ. ПОДРОБНЕЕ ОБ ЭТОМ СМ. ОЛЬГА Е. КОШЕЛЕВА, «БЛАГОСЛОВЛЯЮ ЧАДА СВОИ: ЗАБОТА О ДЕТЯХ (ПО ДРЕВНЕРУССКИМ ДУХОВНЫМ ГРАМОТАМ)», ВЕСТНИК УНИВЕРСИТЕТА РОССИЙСКОЙ АКАДЕМИИ ОБРАЗОВАНИЯ, 1997, № 2, с. 132 -135.

24. О ЧАСТНЫХ АРХИВАХ ХVII В. СМ.: БОРИС Н. МОРОЗОВ, «ЧАСТНЫЕ АРХИВЫ РУССКИХ ФЕОДАЛОВ XVII В.»: ДИСС. КАНД. ИСТ. НАУК, М., 1984; АНТОН В. АНТОНОВ, «ЧАСТНЫЕ АРХИВЫ РУССКИХ ФЕОДАЛОВ XV - НАЧ. ХVII В.» РУССКИЙ ДИПЛОМАТАРИЙ, ВЫП. 8, М., 2002; ЮРИЙ М. ЭСКИН, ОЧЕРКИ ИСТОРИИ МЕСТНИЧЕСТВА В РОССИИ XVI -XVII ВВ., М., 2009, С. 63-74; ОЛЬГА В. НОВОХАТКО, РЕД., АРХИВ СТОЛЬНИКА АНДРЕЯ ИЛЬИЧА БЕЗОБРАЗОВА, Ч. 1-2, М., 2012-2013.

25. АЛЕКСАНДР П. БАРСУКОВ, РОД ШЕРЕМЕТЕВЫХ, В 8-МИ ТОМ., СПБ., 1881-1884.

26. ЕВГЕНИЙ П. К???????,АРНОВИЧ, ЗАМЕЧАТЕЛЬНЫЕ БОГАТСТВА ЧАСТНЫХ ЛИЦ В РОССИИ: ЭКОНОМИКО-ИСТОРИЧЕСКОЕ ИССЛЕДОВАНИЕ, СПБ., 1874, С. 5; ТАТЬЯНА ЗЕМЦОВА, «ВЕЛИЧАЙШЕЕ, ДОСТОЙНОЕ УДИВЛЕНИЯ...ДЕЛО», НАУКА И ЖИЗНЬ, 2013, № 12, С. 149.

27. «ЧИН ПОСТАВЛЕНИЯ НА ЦАРСТВО ЦАРЯ И ВЕЛИКОГО КНЯЗЯ АЛЕКСЕЯ МИХАЙЛОВИЧА. СООБЩИЛ АРХИМАНДРИТ ЛЕОНИД», ПАМЯТНИКИ ДРЕВНЕРУССКОЙ ПИСЬМЕННОСТИ, 16, СПБ., 1882.

28. Russell Martin, A Bride for the Tsar: Bride-Shows and Marriage Politics in Early Modern Russia, DeKalb: Northern Illinois University Press, 2012, c. 141.

29. Ф.И. ШЕРЕМЕТЕВ В 1600 Г., ПРИ ОПАЛЕ РОМАНОВЫХ, БЫЛ ЛИШЕН ЦАРЕМ БОРИСОМ ГОДУНОВЫМ МОСКОВСКОГО ДВОРА И РЯЗАНСКОЙ ВОТЧИНЫ И ОТПРАВЛЕН ВОЕВОДОЙ В ТОБОЛЬСК (ДО 1603 Г.); ИВАН БОРИСОВИЧ ЧЕРКАССКИЙ, ПЛЕМЯННИК ФЕДОРА НИКИТИЧА РОМАНОВА, 
ПОДВЕРГАЛСЯ ДОЗНАНИЮ И ПЫТКЕ, ЗАТЕМ - СОСЛАН В СИБИРЬ (ДО 1602 Г.); О 3-Х СЫНОВЬЯХ КАЗНЕННОГО ИВАНОМ ГРОЗНЫМ БОЯРИНА НИКИТЫ РОМАНОВИЧА ОДОЕВСКОГО В ПРАВЛЕНИЕ ГОДУНОВА ИЗВЕСТНО МАЛО.

30. ПОДРОБНЕЕ СМ.: ОЛЬГА Е. КОШЕЛЕВА, «ГОСУДАРЕВЫ ПОЖАЛОВАНИЯ В БОЯРСКУЮ ДУМУ ПРИ ПЕРВЫХ РОМАНОВЫХ: «НОВЫЕ ЛЮДИ» И «СТАРЫЕ БОЯРЕ», В: ГОСУДАРЕВ ДВОР В ИСТОРИИ РОССИИ XV-XVIII СТОЛЕТИЙ: МАТЕРИАЛЫ МЕЖДУНАРОДНОЙ НАУЧНО-ПРАКТИЧЕСКОЙ КОНФЕРЕНЦИИ, АЛЕКСАНДРОВ-ВЛАДИМИР, 2006, С. 250-254.

31. ЭТИ СВЕДЕНИЯ СОДЕРЖАТСЯ В РОДОСЛОВНОЙ РОДА ШЕРЕМЕТЕВЫХ, СОСТАВЛЕННОЙ А.П. БАРСУКОВЫМ: БАРСУКОВ, РОД ШЕРЕМЕТЕВЫХ, Т. 8, ПРИЛОЖЕНИЯ, С. 7.

32. ТАМ ЖЕ. СМ.: АЛЕКСЕЙ Е. ЧЕКАЛИН, РОД КНЯЗЕЙ ЧЕРКАССКИХ В ИСТОРИИ РОССИИ. ДИСС... НА ЗВАНИЕ КАНД. ИСТ. НАУК., М., 2013.

33. «ДОКЛАДНАЯ ВЫПИСКА 121 (1613 Г.) О ВОТЧИНАХ И ПОМЕСТЬЯХ». АЛЕКСАНДР П. БАРСУКОВ (ПУБЛ.), ЧТЕНИЯ ОБЩЕСТВА ИСТОРИИ И ДРЕВНОСТЕЙ РОССИЙСКИХ, 1895, Т. І, ОТД. 1. ПРИБЛИЗИТЕЛЬНО ТО ЖЕ КОЛИЧЕСТВО ЗЕМЛИ ПОЛУЧАЕТСЯ И ПРИ ПОДСЧЕТАХ ПО ПИСЦОВЫМ КНИГАМ 20-Х ГГ. - 9248 ЧЕТВ. (ОЛЕГ А. ШВАТЧЕНКО, СВЕТСКИЕ ФЕОДАЛЬНЫЕ ВОТЧИНЫ РОССИИ В ПЕРВОЙ ТРЕТИ XVII В., М., 1990, С. 178. ОБЩИЙ ПОДСЧЕТ ЗЕМЛИ И ДВОРОВ ПО ДАННЫМ, ПРИВЕДЕННЫМ О.А. ШВАТЧЕНКО ПО ПИСЦОВЫМ И ПЕРЕПИСНЫМ КНИГАМ (РГАДА, РОССИЙСКИЙ ГОСУДАРСТВЕННЫЙ АРХИВ ДРЕВНИХ АКТОВ, Ф. 1209), СДЕЛАН МНОЙ ЗДЕСЬ И ДАЛЕЕ).

34. ЗАВЕЩАНИЯ КН. И.Б. ЧЕРКАССКОГО НЕ СОХРАНИЛОСЬ, НО ЭТО СТАНОВИТСЯ ЯСНЫМ ИЗ ЗАВЕЩАНИЯ САМОГО Ф.И. ШЕРЕМЕТЕВА.

35. СЕРГЕЙ К. БОГОЯВЛЕНСКИЙ, ПРИКАЗНЫЕ СУДЬИ XVII В., М., 1940. СМ., ТАКЖЕ - ОЛЬГА Е. КОШЕЛЕВА, БОРИС Н. МОРОЗОВ, «СЛУЖЕБНАЯ ДЕЯТЕЛЬНОСТЬ БОЯР В XVII В.», В: Chester S.L. Dunning, Russel E. Martin and Daniel Rowland, eds., Rude and Barbarious Kingdom revisited: Essays in Russian History and Culture in Honor of Robert O. Crummy, Slavica Publishers Indiana University, 2008, c. 9-10.

36. Poe, The Russian Elite in the Seventeenth Century, vol. 1 : The Consular and Ceremonial Ranks of the Russian “Sovereign's court (1613-1713)”, c. 115-154.

37. БАРСУКОВ, РОД ШЕРЕМЕТЕВЫХ, Т. 8, ПРИЛОЖЕНИЯ, С. 8.

38. «ДУХОВНАЯ ЕВДОКИИ ФЕДОРОВНЫ ОДОЕВСКОЙ, 1671 Г.» В: БАРСУКОВ, РОД ШЕРЕМЕТЕВЫХ,1899, Т. 7, С. 343-350.

39. СЕРГЕЙ В. РОЖДЕСТВЕНСКИЙ, «РОСПИСЬ ЗЕМЕЛЬНЫХ ВЛАДЕНИЙ МОСКОВСКОГО БОЯРСТВА 1647/48 ГОДА», ДРЕВНОСТИ: ТРУДЫ АРХЕОГРАФИЧЕСКОЙ КОМИССИИ ИМП. МОСКОВСКОГО АРХЕОЛОГИЧЕСКОГО ОБЩЕСТВА, Т. 3, М., 1918, СТЛБ. 193-195.

40. «ДУХОВНОЕ ЗАВЕЩАНИЕ БОЯРИНА ФЕДОРА ИВАНОВИЧА ШЕРЕМЕТЕВА 1645 Г.», БАРСУКОВ, РОД ШЕРЕМЕТЕВЫХ, СПЬ., 1883, Т. 3, С. 495-510; «ИЗУСТНАЯ ПАМЯТЬ БОЯРИНА ФЕДОРА ИВАНОВИЧА ШЕРЕМЕТЕВА», ТАМ ЖЕ, С. 510-524.

41. «ИЗУСТНАЯ ПАМЯТЬ БОЯРИНА ФЕДОРА ИВАНОВИЧА ШЕРЕМЕТЕВА», С. 510-524.

42. «ДУХОВНОЕ ЗАВЕЩАНИЕ БОЯРИНА ФЕДОРА ИВАНОВИЧА ШЕРЕМЕТЕВА 1645 Г.».

43. «ДУХОВНАЯ КН. ЕВДОКИИ ФЕДОРОВНЫ ОДОЕВСКОЙ, 1671 Г.», БАРСУКОВ, РОД ШЕРЕМЕТЕВЫХ, 1899 , т. 7, С. 348-349.

44. ЯРОСЛАВ Е. ВОДАРСКИЙ, «ПРАВЯЩАЯ ГРУППА СВЕТСКИХ ФЕОДАЛОВ В РОССИИ В XVII В.», В: ДВОРЯНСТВО И КРЕПОСТНОЙ СТРОЙ В РОССИИ В XVI - XVI ВВ. М., 1975, С. 95.

45. «ДУХОВНАЯ БОЯРИНА КН. НИКИТЫ ИВАНОВИЧА ОДОЕВСКОГО (1689 Г.)», ИЗВЕСТИЯ РУССКОГО ГЕНЕАЛОГИЧЕСКОГО ОБЩЕСТВА, 1911, № 4, С. 379 - 391.

46. «ДУХОВНАЯ БОЯРИНА КН. НИКИТЫ ИВАНОВИЧА ОДОЕВСКОГО (1689 Г.)», С. 6.

47. РГАДА, Ф. 994, Д. 309, Л. 2, 2 ОБ.

48. РГАДА, Ф. 994, Д. 309, Л. 20 - 27. 
49. «ПОСЛАНИЕ ЦАРЯ АЛЕКСЕЯ МИХАЙЛОВИЧА КНЯЗЮ НИКИТЕ ИВАНОВИЧУ ОДОЕВСКОМУ, 1652 Г.», ЗАПИСКИ ОТДЕЛЕНИЯ РУССКОЙ И СЛАВЯНСКОЙ АРХЕОЛОГИИ ИМПЕРАТОРСКОГО РУССКОГО АРХЕОЛОГИЧЕСКОГО ОБЩЕСТВА, Т. 2, СПБ., 1861, С. 705-706.

50. СЕРГЕЙ М. СОЛОВЬЕВ, ИСТОРИЯ РОССИИ С ДРЕВНЕЙШИХ ВРЕМЕН, М., 1961, КН. 6, С. 619 - 620.

51. ИМЯ ЖЕНЫ КН. Я.Н. ОДОЕВСКОГО ТОЧНО НЕИЗВЕСТНО, ПРЕДПОЛОЖИТЕЛЬНО ЭТО КНЯЖНА АННА МИХАЙЛОВНА ПРОНСКАЯ.

52. ПО ДУХОВНОЙ ГРАМОТЕ КН. Д.М. ЧЕРКАССКОГО 1651 Г. ПОЧТИ ВСЕ ЕГО ЗЕМЛИ ПЕРЕХОДИЛИ К КН. Я.К. ЧЕРКАССКОМУ, К НЕМУ ЖЕ ПО ЗАВЕЩАНИЮ 1643 Г. ОТОШЛА ЧАСТЬ ЗЕМЕЛЬ БОЯРИНА Ю.Я. СУЛЕШОВА (528 ЧЕТЕЙ).

53. РОЖДЕСТВЕНСКИЙ, «РОСПИСЬ ЗЕМЕЛЬНЫХ ВЛАДЕНИЙ МОСКОВСКОГО БОЯРСТВА 1647/48 ГОДА»; НИКОЛАЙ К. НИКОЛЬСКИЙ, КИРИЛЛО-БЕЛОЗЕРСКИЙ МОНАСТЫРЬ И ЕГО УСТРОЙСТВО ДО ВТОРОЙ ЧЕТВЕРТИ ХVII В., СПБ., 1896, Т. 1, ПРИЛОЖЕНИЕ 1.

54. МАРИЯ КРЮЧКОВА, «ВОТЧИНА КНЯЗЬ ДМИТРЕЯ КНЯЖ МИХАЙЛОВА СЫНА ГОЛИЦЫНА», НАШЕ НАСЛЕДИЕ, 1992, № 92.

55. МАРШАЛ ПО, «РОССИЙСКАЯ ЭЛИТА В XVII В. ДУМНЫЕ И ЦЕРЕМОНИАЛЬНЫЕ ЧИНЫ ГОСУДАРЕВА ДВОРА (1613-1713)», Т. 1, с. 462.

56. РГАДА, Ф. 210, ОП. 2, Д. 28, Л. 23.

57. О НЕМ МОЖНО СУДИТЬ ПО УЧЕБНОЙ РУКОПИСИ С ОБРАЩЕНИЕМ К РОДИТЕЛЯМ ПЕТРА И АЛЕКСЕЯ ЧЕРКАССКИХ - РНБ. Q. І. 327, Л. 22.

58. ЕВГЕНИЙ В. АНИСИМОВ, «ИСКУССТВО ДРЕМАТЬ БЕЗ УЩЕРБА ДЛЯ БИОГРАФИИ», ДВОРЦОВЫЕ ТАЙНЫ, СПБ., 2007, С. 21-23.

59. СЧИТАЕТСЯ, ЧТО КН. А.М. ЧЕРКАССКИЙ РОДИЛСЯ В 1681 Г., НО ПЕРЕПИСЬ 1718 Г. УТВЕРЖДАЕТ, ЧТО А.М. ЧЕРКАССКОМУ 34 ГОДА, Т.Е. ОН РОДИЛСЯ В 1684. УМЕР В 1742 Г. В ДОЛЖНОСТИ ПРЕЗИДЕНТА ИНОСТРАННОЙ КОЛЛЕГИИ И ВЕЛИКОГО КАНЦЛЕРА.

60. РГАДА, Ф. 26, ОП. 3, Д. 8451-8662, Л. 328 - 330.

61. ТАМ ЖЕ.

62. Crummey, Aristocrats and Servitors, c. 113.

63. ПОД «КОСВЕННЫМИ» НАСЛЕДНИКАМИ, ВИДИМО, ИМЕЕТСЯ В ВИДУ ЗЯТЬ ШЕРЕМЕТЕВА КН. Н.И. одОЕВСКИЙ.

64. Crummey, Aristocrats and Servitors, c.122.

65. БОРИС КЕМБУЛАТОВИЧ ЧЕРКАССКИЙ, ДМИТРИЙ МАМСТРЮКОВИЧ ЧЕРКАССКИЙ, ГРИГОРИЙ СУНГАЛЕЕВИЧ ЧЕРКАССКИЙ, ЯКОВ КУДЕНЕТОВИЧ ЧЕРКАССКИЙ.

66. ЧЕКАЛИН, РОД КНЯЗЕЙ ЧЕРКАССКИХ В ИСТОРИИ РОССИИ.

67. Valerie A. Kivelson. «The Effects of Partible Inheritance: Gentry Families and the State in Muscovy», The Russian Review, 53, April 1994, c. 211.

68. В ЦЕЛОМ АНАЛИЗ ДРЕВНЕРУССКИХ ЗАВЕЩАНИЙ ПОКАЗЫВАЕТ, ЧТО МЛАДШИМ СЫНОВЬЯМ НЕБОГАТЫХ ПОМЕЩИКОВ ОБЫЧНО ДОСТАВАЛАСЬ МЕНЬШАЯ И ХУДШАЯ ДОЛЯ ЗЕМЛИ ПО СРАВНЕНИЮ СО СТАРШИМИ. ЗАТО МЛАДШИЙ СЫН ВСЕГДА НАСЛЕДОВАЛ РОДИТЕЛЬСКИЙ ДОМ (ПОДРОБНЕЕ СМ.: ОЛЬГА Е. КОШЕЛЕВА, «БЛАГОСЛОВЛЯЮ ЧАДА СВОИ ...» С. 112-116.

69. ШВАТЧЕНКО, СВЕТСКИЕ ФЕОДАЛЬНЫЕ ВОТЧИНЫ РОССИИ В ПЕРВОЙ ТРЕТИ ХVII В., С. 178.

70. ТАМ ЖЕ, С. 177-178. ЗДЕСЬ Я НЕ ПРИВОЖУ МЕСТОНАХОЖДЕНИЕ ВОТЧИН.

71. ТАМ ЖЕ.

72. ТАМ ЖЕ.

73. НИКОЛЬСКИЙ, КИРИЛЛО-БЕЛОЗЕРСКИЙ МОНАСТЫРЬ И ЕГО УСТРОЙСТВО ДО ВТОРОЙ ЧЕТВЕРТИ ХVII В., Т. 1, ПРИЛОЖЕНИЕ 1.

74. ВОДАРСКИЙ, «ПРАВЯЩАЯ ГРУППА СВЕТСКИХ ФЕОДАЛОВ В РОССИИ В XVII В.», С. 103-104.

75. БАРСУКОВ, РОД ШЕРЕМЕТЕВЫХ, Т. 3, С. 361. 
76. «ИЗУСТНАЯ ПАМЯТЬ ВАСИЛИЯ БОРИСОВИЧА ШЕРЕМЕТЕВА», В: БАРСУКОВ, РОД ШЕРЕМЕТЕВЫХ, T. 8, 1904, С. $506-511$.

77. НАТАЛЬЯ КОЗЛОВА И АЛЕКСАНДРА ПРОКОФЬЕВА, СОСТАВ., ДВОРЯНЕ МОСКВЫ: СВАДЕБНЫЕ АКТЫ И ДУХОВНЫЕ ЗАВЕЩАНИЯ ПЕТРОВСКОГО ВРЕМЕНИ, М., 2015, с. 10.

78. ЮРИЙ М. Э????,СКИН, МЕСТНИЧЕСТВО В РОССИИ ХVI-ХVII ВВ. ХРОНОЛОГИЧЕСКИЙ РЕЕСТР, М., 1994, C. 181.

79. СОЛОВЬЕВ, ИСТОРИЯ РОССИИ С ДРЕВНЕЙШИХ ВРЕМЕН, КН. 6, С. 619.

80. В ВОПРОСЕ О ТОМ, КТО БЫЛ МАТЕРЬЮ «ПЕТРОВИЧЕЙ» - НАГАЯ ИЛИ ДОЛГОРУКАЯ - МНЕНИЯ РАСХОДЯТСЯ.

81. СВЕДЕНИЯ ИЗ: БАРСУКОВ, РОД ШЕРЕМЕТЕВЫХ, 1881-1884; КОЗЛОВА И ПРОКОФЬЕВА, СОСТАВ., ДВОРЯНЕ МОСКВЫ: СВАДЕБНЫЕ АКТЫ И ДУХОВНЫЕ ЗАВЕЩАНИЯ ПЕТРОВСКОГО ВРЕМЕНИ.

82. КНЯЗЬЯ ОДОЕВСКИЕ, ВОРОТЫНСКИЕ, МСТИСЛАВСКИЕ, ЛИТВИНОВЫ - МОСАЛЬСКИЕ, МЕЗЕЦКИЕ.

83. РОБЕРТ О. КРАММИ, «ИСТОЧНИКИ БОЯРСКОЙ ВЛАСТИ В XVII В.: ПОТОМКИ СЛУЖИЛЫХ КНЯЗЕЙ С ВЕРХОВЬЕВ ОКИ», ВЫСТУПЛЕНИЕ НА 1-ЫХ ЗИМИНСКИХ ЧТЕНИЯХ (НЕ ОПУБЛИКОВАНО - hand out).

84. ВЛАДИСЛАВ Д.Н?????АЗАРОВ , «КНЯЗЬЯ РОМОДАНОВСКИЕ В ЭПОХУ СТАНОВЛЕНИЯ РОССИЙСКОГО ЦЕНТРАЛИЗОВАННОГО ГОСУДАРСТВА (ФАМИЛЬНЫЙ ПОРТРЕТ В РОДОВОМ ИНТЕРЬЕРЕ И СОЦИОЛОГИЧЕСКОМ КОНТЕКСТЕ)», ГОСУДАРЕВ ДВОР В ИСТОРИИ РОССИИ XV-XVIII СТОЛЕТИЙ: МАТЕРИАЛЫ МЕЖДУНАРОДНОЙ НАУЧНО-ПРАКТИЧЕСКОЙ КОНФЕРЕНЦИИ, АЛЕКСАНДРОВ-ВЛАДИМИР, 2006, С. 74.

85. ЛОБАЧЕВ, «ИЗУЧЕНИЕ ГЕНЕАЛОГИИ БОЯРСКОЙ АРИСТОКРАТИИ...», С. 317.

86. Kivelson, The Effects of Partible Inheritance.

87. РОЖДЕСТВЕНСКИЙ, «РОСПИСЬ ЗЕМЕЛЬНЫХ ВЛАДЕНИЙ МОСКОВСКОГО БОЯРСТВА 1647/48 ГОДА», СТЛБ. 227-230.

88. ОЛЬГА Е. КОШЕЛЕВА, «БОЯРСТВО В НАЧАЛЬНЫЙ ПЕРИОД ЗАРОЖДЕНИЯ АБСОЛЮТИЗМА В РОССИИ (1645-1682 ГГ.)», ДИСС. НА СОИСКАНИЕ УЧЕНОЙ СТЕПЕНИ КАНД. ИСТ. НАУК. М., 1987, С. 82-87 И ПРИЛОЖЕНИЕ 7.

\section{RÉSUMÉS}

L'historiographie existante ne permet pas de connaître les raisons qui guidaient le choix des partenaires de mariage dans les «clans» de bojare. En assumant l'usage de la notion anachronique du «clan", l'auteur ne l'interprète pas comme un synonyme de lignage ou de famille, mais lui confère le sens d'alliance entre plusieurs familles, alliance fondée sur les liens du mariage et le partage de la propriété foncière. L'auteur se base sur l'histoire des familles Šeremet 'ev, Odoevskij et Čerkasskij pour étudier les stratégies de mariage. Ces lignages cultivaient des liens de famille forts. Contrairement à ses prédécesseurs, qui attribuaient une place éminente au service et à la faveur du tsar, l'auteur souligne ici l'importance des valeurs familiales: 1) perpétuation du lignage grâce à une progéniture mâle robuste ; 2) soutien économique des successeurs par la transmission des terres ; 3) permanence de commémoration sprirituelle des parents décédés; 4) maintien de la memoria glorieuse de la famille. L'auteur s'attache à démontrer que ces valeurs constituent les fondements de la stratégie familiale des bojare. L'étude révèle aussi les différences dans les stratégies maritales entre les deux branches des Šeremet'ev. La première (Sheremet'ev - Odoevskij - Čerkasskij) ne concluait pas de mariage en dehors de l'élite des boyare. Les terres étaient étroitement contrôlées. Les filles, grâce à leurs dots, 
contribuaient à cette stratégie, en transmettant leurs biens à leurs enfants et petits-enfants. Le clan avait pour tradition et caractéristique de concentrer le gros de ses biens sur un seul héritier. En revanche, l'autre branche des Sheremet'ev, ne se limitait pas à l'élite des bojare, et il était fréquent que les épouses fussent choisies dans des familles nobles. La stratégie était fonction des circonstances. Ainsi, même si cet article ne résout pas entièrement le mystère de la logique maritale chez les bojare, il prouve clairement qu'elle ne fut pas unique ni invariable.

Up to the present, the reasoning behind the choice of marriage partners in boyar clans has remained a historiographical mystery. Re-thinking the historiographically anachronistic definition of "clan," the author treats this concept as not being identical to the notion of "lineage" or "family," but rather as an alliance of several families founded on marriage ties and common landholdings. In the article, marriage strategies are examined on the basis of data on the Sheremet'ev, Odoevskii and Cherkasskii families. These lineages created strong family ties. Most research in this area is focused on the importance of government service and the monarch's favor. The author, in contrast, foregrounds the importance of the following family values: (1) the continuation of the family line through healthy male progeny; (2) the support of this progeny through landholdings; (3) the continuous religious commemoration of all the deceased; and (4) the maintenance of the glorious memoria of the family. In the article, the above values are examined as the foundation of boyar family strategy. The article also reveals variations in the marriage strategies of two branches of the Sheremet'ev line. One branch, the Sheremet'ev-Odoevskii-Cherkasskii, did not have any marriages with persons outside the highest boyar elite. The landholdings of this clan were maintained within its control. Daughters played an important role in this process through their dowries, which were inherited by their children and grandchildren. This clan was characterized by its particular custom of passing on the greater mass of landholdings to one heir, with the smaller parts going to the rest. Looking at another branch of the Sheremet'ev family, the author notes that this branch did not limit their choice of marriage partners to the boyar elite. They often took brides from gentry families. Marriage strategy was defined by circumstance. If the logic of boyar marriage choice is still not totally clarified, we may nonetheless assert that it was not one and the same for all boyar clans.

\section{AUTEUR}

\section{OLGA KOSHELEVA}

Institut d'histoire universelle Académie des sciences de Russie, Moscou, okosheleva@mail.ru 